\title{
A new tool to simulate ground shaking and earthquake losses
}

Fernando López Hidalgo ( $\square$ fernando.lopez.hidalgo@juntadeandalucia.es )

Junta de Andalucia https://orcid.org/0000-0003-1959-063X

Manuel Navarro

Universidad de Almeria

Sergio Molina

Universidad de Alicante

\section{Research Article}

Keywords: Emergency planning, Shakemaps, Vulnerability, Damage scenarios, GIS.

Posted Date: June 7th, 2021

DOl: https://doi.org/10.21203/rs.3.rs-313632/v1

License: (c) (i) This work is licensed under a Creative Commons Attribution 4.0 International License.

Read Full License 


\section{A new tool to simulate ground shaking and earthquake losses}

\section{López $\mathbf{F}^{1, *}$, a, Navarro $\mathbf{M}^{2}$, Molina $\mathbf{S}^{3}$}

$3 \quad{ }^{1}$ Civil Protection Service of Junta de Andalucía, Almería, Spain

$4 \quad{ }^{2}$ Universidad de Almería, Dpto de Química y Física, Almería, Spain

53 Universidad de Alicante, Dpto de Física Aplicada, Alicante, Spain

6

7 Acknowledgments: The authors gratefully acknowledge the support provided by the Civil 8 Protection Staff of Junta de Andalucía. We would like to thank Antonio Posadas Chinchilla for 9 helping in the revision of manuscript. We also thank anonymous referees by the constructive 10 comments significantly improved this article.

\section{Declarations}

Funding: The Spanish Science and Innovation Ministry (Research Project CGL2011- 30187-C0202) and CGL2016-77688-R (AEI/FEDER, UE) have funded this research.

Conflicts of interest: The authors declare that they have no known competing financial interests or personal relationships that could have appeared to influence the work reported in this paper. Code availability: SISMOTOOL has been developed by López F and the first beta version was available in 2019. SISMOTOOL has been encoded to be part of the toolbar of the software ARCGIS and works through an Add-in type customization. In this case, the VB.NET language and the ArcObjects software development kit integrated into a Microsoft Visual Studio programming environment have been used and the source code of the Visual Studio project is provided. Besides, any developer will have the possibility of modifying the tool or even including new functionalities just modifying the Visual Studio code.

LINK TO THE CODE:

https://drive.google.com/file/d/1ED6H56OAVwQvduTswVADrmoZkujt8Ir8/view?usp=sharing

Authors' contributions: LF has conceived the idea of the tool, elaborated the necessary programming code and has drafted the manuscript. NM and MS have investigated the theoreticalanalytical state of the art and have designed and revised the manuscript. All authors discussed the results and conclusions.

${ }^{*}$ Corresponding Author.

E-mail addresses: fernando.lopez.hidalgo@juntadeandalucia.es (López F), mnavarro@ual.es (Navarro M), sergio.molina@gcloud.ua.es (Molina S).

ORCID numbers: 0000-0003-1959-063X (López F), 0000-0002-5462-0809 (Navarro M), 0000-0002-89096285 (Molina S).

aTelephone: +34677903886, Present postal adress: 8 Canónigo Molina Street, Floor 7, Almeria, 04071, Spain. 
The main purpose of SISMOTOOL suite is Planning and Management of Seismic Emergencies face to a future earthquake. This tool is written in ARCGIS software executing a fast and efficient determination of the estimated damage scenarios (pre-process) and a correlation with the observed damage results (post-process).

First of all, the tool allows to select the earthquake source parameters through a defined database; moreover, several attenuation laws can be chosen and they can be combined according to the study area features. In addition, the local site effects are characterized from Vs30 values, which have been achieved by: i) topographic slope as a proxy obtained from Digital Elevation Model; ii) considering Vs30 values acquired from active and/or passive empirical methods; iii) a combination of both procedures through empirical local correlation laws. In the second place, the elements exposed to risk are incorporated by an automatic extraction from the cadastral database after inputs has been refined. Thirdly, vulnerability and estimated losses can be determined either empirically (EMS98 scale and Vulnerability Index, Iv) or analytically (Capacity spectrum). Additionally, a vulnerability modifier is implemented to account soil-structure resonance. Finally, SISMOTOOL quantifies the epistemic uncertainties in the input parameters using a logic tree. Last, but not least, SISMOTOOL results have been validated through a representative seismic scenario: the 1910 Adra earthquake (southern Spain) with moment magnitude $\left(M_{w}\right) 6.3$ and macroseismic intensity VIII (EMS98 scale) proves the reliability of SISMOTOOL program. 


\section{Introduction}

Seismic risk management involves the physical and structural consequences of an earthquake and the socio-economic considerations affecting the current population or even future generations. Therefore, it integrates evaluation of the risk and the corresponding adopted decisions in order to improve the seismic resilience.

The Iberian Peninsula shows a low to moderate seismicity in the world context with frequent earthquakes of $M_{w}$ generally smaller than 5.5, although, historically, large damaging earthquakes have occurred with epicentral macroseismic intensity $\left(I_{0}\right)$ IX-X in the EMS-98 scale, as those of 1829 Torrevieja (Alicante) and 1884 Arenas del Rey (Granada). Both earthquakes caused the collapse of many buildings and a high number of human losses (Vidal 1986).

Recently, several instrumental earthquakes occurred in southeast of Spain, such as: Adra (Almería) 1993 and 1994; Mula (Murcia) 1999; Bullas (Murcia) 2002; La Paca (Murcia) 2005 and Lorca (Murcia) 2011, with magnitudes $\left(M_{w}\right)$ between 4.7 and 5.2 respectively, and $I_{0}$ ranging from V to VII (EMS-98 scale). Theses shocks have shown the relevance of shallow geology for explaining not only the ground motion amplification but 2014; Benito et al. 2007; García-Jerez et al. 2007; Alguacil et al. 2014).

Consequently, preventive decision-making aimed at doing recommendations for the mitigation of seismic risk is more effective if seismic emergency managers (Civil Protection) have user-friendly software capable of estimating damage and loss scenarios in future earthquakes. This information is essential to develop Seismic Emergency Plans at local level for the municipalities, because they establish the organization scheme and action procedures needed to effectively deal with the earthquake emergency. Such a devices are of great importance for any seismically active region, regardless of the level of seismic hazard.

One of the first seismic risk suite in Spain having this goal in mind is "Simulador de

87 Escenarios Sísmicos-SES2002" (SES 2002). This software was created specifically for 
the Civil Protection and although it has been widely used, nowadays it is not up to date due to a huge number of factors: current development of the scientific methodologies, improvements in the definition of vulnerability and, of course, the enormous change in the building stock and the population since SES 2002 was coded twenty years ago.

After the development of HAZUS (FEMA 1999), known as a reference for the earthquake losses estimations, numerous modelling tools have been developed by scientists worldwide to estimate seismic risk. Many of these programs were planned mainly focused on the scientific community but providing results also useful for the civil protection system. For example, SEISMOCARE (Anagnostopoulosa et al. 2008), Seismic Loss Estimation using a logic tree Approach-SELENA (Molina et al. 2010), Central American Probabilistic Risk Assessment-CAPRA (Cardona et al. 2012), Armagedom (Sedan et al. 2013) and OPENQUAKE (Pagani et al. 2014) were created for assessment and estimation of losses. Table 1 shows a summary of these tools with a brief comparison in terms of methodologies and results.

Therefore, the aim of this paper is to show a new tool (SISMOTOOL) integrating strengths of the known platforms (see Table 1) and incorporating new methodologies (which are crucial when computing shakemaps and losses scenarios for the emergency planning). In particular, SISMOTOOL can automatically: a) compute a number of parameters such as amplification factors due to geology and topographic effects by using digital elevation models (DEM); b) assign and classify the vulnerability of the building stock through the cadastral database (DB) as well as other improvements, always with the highest processing speed. Therefore, any stakeholder or emergency planner will be able to make decisions nearly in "real-time" by handling SISMOTOOL program. 
116 Table 1 Summary of some of the main Earthquake Loss Estimation (ELE) tools currently published and the

117 comparison with SISMOTOOL

\begin{tabular}{|c|c|c|c|c|c|c|c|c|}
\hline Tools & $\begin{array}{l}\text { HAZUS } \AA \text { (FEMA } \\
\text { 1999) }\end{array}$ & SES 2002 & $\begin{array}{l}\text { SEISMOCARE } \\
\text { (Anagnostopoulus } \\
\text { et al. 2008) }\end{array}$ & $\begin{array}{l}\text { SELENA } \\
\text { (Molina et al. } \\
\text { 2010) }\end{array}$ & $\begin{array}{l}\text { CAPRA } \\
\text { (Cardona et al. } \\
\text { 2012) }\end{array}$ & $\begin{array}{l}\text { Armagedom } \\
\text { (Sedan et al. } \\
\text { 2013) }\end{array}$ & $\begin{array}{l}\text { OPENQUAKE } \\
\text { (Pagani et al. } \\
\text { 2014) }\end{array}$ & SISMOTOOL \\
\hline $\begin{array}{l}\text { GIS } \\
\text { inteqration }\end{array}$ & ESRI ArcGis & $\begin{array}{l}\text { Map Objects } \\
\text { (own GIS) }\end{array}$ & MapInfo & No & Own GIS & Own GIS & No & ESRI ArcGis \\
\hline Open Source & No & No & No & Yes & No & No & Yes & Yes \\
\hline $\begin{array}{l}\text { Seismic } \\
\text { scenario }\end{array}$ & $\begin{array}{l}\text { Deterministic } \\
\text { Probabilistic }\end{array}$ & Deterministic & Deterministic & $\begin{array}{l}\text { Deterministic } \\
\text { Probabilistic }\end{array}$ & Probabilistic & $\begin{array}{l}\text { Deterministic } \\
\text { Probabilistic }\end{array}$ & $\begin{array}{l}\text { Deterministic } \\
\text { Probabilistic }\end{array}$ & $\begin{array}{l}\text { Deterministic } \\
\text { PGA Map }\end{array}$ \\
\hline $\begin{array}{l}\text { Ground } \\
\text { motion } \\
\text { parameter }\end{array}$ & $\begin{array}{l}\text { Spectral } \\
\text { acceleration }\end{array}$ & $\begin{array}{l}\text { Macroseismic } \\
\text { intensity }\end{array}$ & PGA & $\begin{array}{l}\text { Spectral } \\
\text { acceleration }\end{array}$ & PGA & $\begin{array}{l}\text { Macroseismic } \\
\text { intensity } \\
\text { Spectral } \\
\text { acceleration }\end{array}$ & $\begin{array}{l}\text { Spectral } \\
\text { acceleration }\end{array}$ & $\begin{array}{l}\text { Spectral } \\
\text { acceleration }\end{array}$ \\
\hline $\begin{array}{l}\text { Site effects: } \\
\text { Vs30 values } \\
\text { and } \\
\text { topography } \\
\text { factors }\end{array}$ & $\begin{array}{l}\text { Yes (soil } \\
\text { amplification factor } \\
\text { or amplified } \\
\text { shakemaps) given } \\
\text { by users }\end{array}$ & No & $\begin{array}{l}\text { Yes (soil } \\
\text { amplification factors) } \\
\text { given by users }\end{array}$ & $\begin{array}{l}\text { Yes (soil } \\
\text { amplification } \\
\text { factor; } \\
\text { amplified } \\
\text { shakemaps } \\
\text { and } \\
\text { topographic } \\
\text { amplification } \\
\text { factors) given } \\
\text { by users }\end{array}$ & $\begin{array}{l}\text { Yes } \\
\text { (computation of } \\
\text { amplified } \\
\text { shakemaps } \\
\text { using transfer } \\
\text { functions) given } \\
\text { by users }\end{array}$ & $\begin{array}{l}\text { Yes (soil raster } \\
\text { file, Liquefaction } \\
\text { susceptibility } \\
\text { raster file, } \\
\text { landslide } \\
\text { susceptibility } \\
\text { raster file) given } \\
\text { by users }\end{array}$ & $\begin{array}{l}\text { Yes (soil } \\
\text { amplification } \\
\text { factors) given by } \\
\text { users }\end{array}$ & $\begin{array}{l}\text { Yes (soil } \\
\text { amplification } \\
\text { factor; amplified } \\
\text { shakemaps and } \\
\text { topographic } \\
\text { amplification } \\
\text { factors) given by } \\
\text { users or } \\
\text { computed by the } \\
\text { tool }\end{array}$ \\
\hline Exposure & $\begin{array}{l}\text { Buildings } \\
\text { Infrastructures } \\
\text { Population }\end{array}$ & $\begin{array}{l}\text { Buildings } \\
\text { Population }\end{array}$ & $\begin{array}{l}\text { Buildings } \\
\text { Infrastructures } \\
\text { Population }\end{array}$ & $\begin{array}{l}\text { Buildings } \\
\text { Population }\end{array}$ & $\begin{array}{l}\text { Buildings } \\
\text { Population }\end{array}$ & $\begin{array}{l}\text { Buildings } \\
\text { Population }\end{array}$ & $\begin{array}{l}\text { Buildings } \\
\text { Infrastructures } \\
\text { Population }\end{array}$ & $\begin{array}{l}\text { Buildings } \\
\text { Population }\end{array}$ \\
\hline $\begin{array}{l}\text { Interface to } \\
\text { generate } \\
\text { vulnerable } \\
\text { elements }\end{array}$ & No & No & No & No & No & Yes & No & Yes \\
\hline $\begin{array}{l}\text { Vulnerability } \\
\text { estimate }\end{array}$ & $\begin{array}{l}\text { USA buildings } \\
\text { typologies }\end{array}$ & No & No & No & No & Yes & No & $\begin{array}{l}\text { World-wide } \\
\text { buildings } \\
\text { typologies }\end{array}$ \\
\hline $\begin{array}{l}\text { Resonance } \\
\text { Soil-Building }\end{array}$ & No & No & No & No & No & No & No & Yes (empirical) \\
\hline $\begin{array}{l}\text { Damage } \\
\text { computation }\end{array}$ & Analytical & Empirical & Empirical & Analytical & Analytical & $\begin{array}{l}\text { Empirical } \\
\text { Analytical }\end{array}$ & Analytical & $\begin{array}{l}\text { Empirical } \\
\text { Analytical }\end{array}$ \\
\hline $\begin{array}{l}\text { Results } \\
\text { Viewer }\end{array}$ & $\begin{array}{l}\text { Buildings, lifelines } \\
\text { and essential } \\
\text { facilities damage. } \\
\text { Fire-following } \\
\text { earthquake and } \\
\text { Debris generation. } \\
\text { Economic losses, } \\
\text { Casualties and } \\
\text { Shelter. } \\
\text { Indirect Losses }\end{array}$ & $\begin{array}{l}\text { Seismic } \\
\text { intensity. } \\
\text { Building } \\
\text { damage. } \\
\text { Casualties }\end{array}$ & $\begin{array}{l}\text { Building } \\
\text { damage. } \\
\text { Casualties. } \\
\text { Cost of damage }\end{array}$ & $\begin{array}{l}\text { Shakemaps in } \\
\text { terms of } \\
\text { spectral } \\
\text { acceleration. } \\
\text { Building } \\
\text { damage. } \\
\text { Casualties. } \\
\text { Cost } \\
\text { damage. of } \\
\text { Estimation of } \\
\text { debris and } \\
\text { shelter } \\
\text { requirements } \\
\end{array}$ & $\begin{array}{l}\text { Physical } \\
\text { exposure of } \\
\text { construction. } \\
\text { Direct economic } \\
\text { losses. } \\
\text { Probabilistic } \\
\text { Risk: Average } \\
\text { annual loss and } \\
\text { Probable } \\
\text { maximum loss. }\end{array}$ & $\begin{array}{l}\text { Shakemaps in } \\
\text { terms of intensity } \\
\text { and spectral } \\
\text { acceleration. } \\
\text { Building } \\
\text { damage. } \\
\text { Casualties }\end{array}$ & $\begin{array}{l}\text { Loss of life. } \\
\text { Property } \\
\text { damage } \\
\text { and social and } \\
\text { economic } \\
\text { disruption due to } \\
\text { earthquakes }\end{array}$ & $\begin{array}{l}\text { Shakemaps in } \\
\text { terms of intensity } \\
\text { and spectral } \\
\text { acceleration. } \\
\text { Building and } \\
\text { dwelling } \\
\text { Damages. } \\
\text { Economic } \\
\text { losses. } \\
\text { Casualties and } \\
\text { Shelter }\end{array}$ \\
\hline
\end{tabular}

118

1192 Methodology

1202.1 GIS environment and databases (DB)

121 On the one hand, SISMOTOOL is coded to be part of the ARCGIS toolbar (Fig. 1)

122 because, nowadays, it is one of the world's most powerful mapping and analytics

123 software. The current version of SISMOTOOL works through an Add-in type ARCGIS

124 customization; actually, VB.NET language and the ArcObjects software development kit

125 integrated into a Microsoft Visual Studio programming environment are used to write the

126 code of the tool. Since ARCGIS is a commercial software, it is not unusual that 
stakeholders and emergency planners in the municipalities have it installed in their office and have expertise in its use; and even more, SISMOTOOL extension is an open source code and, therefore, the source code of the Visual Studio project is provided, i.e. it can be specifically adapted either any user or a free GIS (for instance, QGIS).

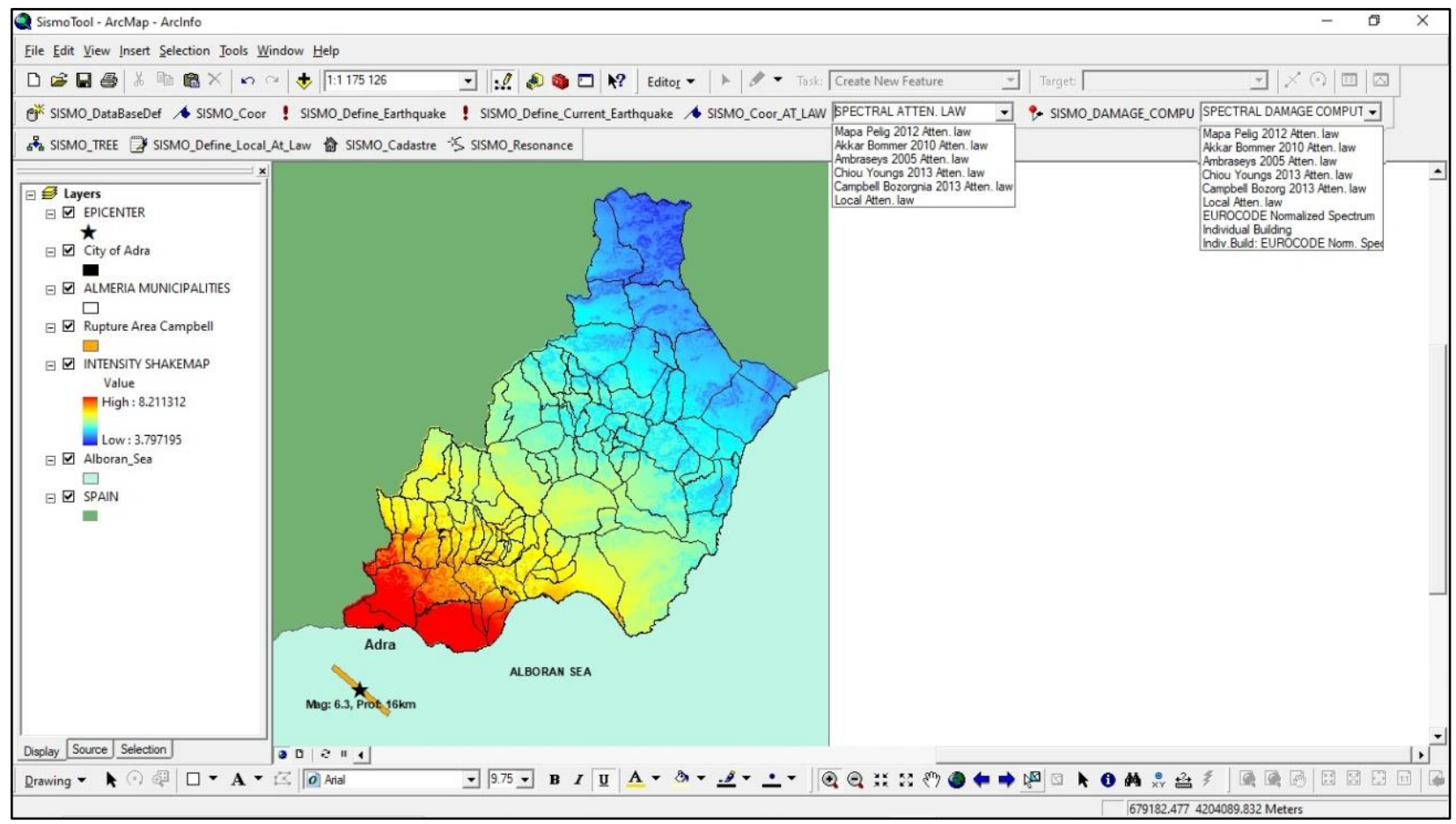

Fig. 1 SISMOTOOL toolbar within the ARCGIS framework showing and intensity shakemap for Almeria (Spain) automatically prepare all the needed DB for an accurate earthquake losses estimation; in other words, Seismic catalogue DB (e.g. IGN 2019), Quaternary faults DB of Iberia (IGME 2015), Hydrographic network and DEM (IDEA 2010), Cadastral information (SEC 2018) and Population information (INE 2018) could be directly incorporated into the analysis. 
1442.2 Earthquake loss estimation methodology implemented in 145 SISMOTOOL

146 The main sequence of running SISMOTOOL is shown in Figure 2, while Figure 3

147 summarizes the steps given during that sequence. To begin with, user will introduce some

148 data in every step through the SISMOTOOL tool bar (Fig. 1) and then, executed within

149 ARCGIS.

150 The seismic emergency planning needs the computation of seismic damage and 151 losses results at least as accurate as the final map scale. Therefore, SISMOTOOL 152 implements programming tools capable of the generation of raster files with spatial 153 resolution up to $5 \mathrm{~m}$ pixel, thus, it could provide to user multi-scale maps. In order to 154 access, to create and to edit the raster files, ArcObjets elements are used, particularly the 155 RasterCursor class, which controls the enumeration through PixelBlocks. As a matter of 156 fact, RasterCursor class is very useful for handling raster files that are too large to be 157 loaded in memory at once.

158 


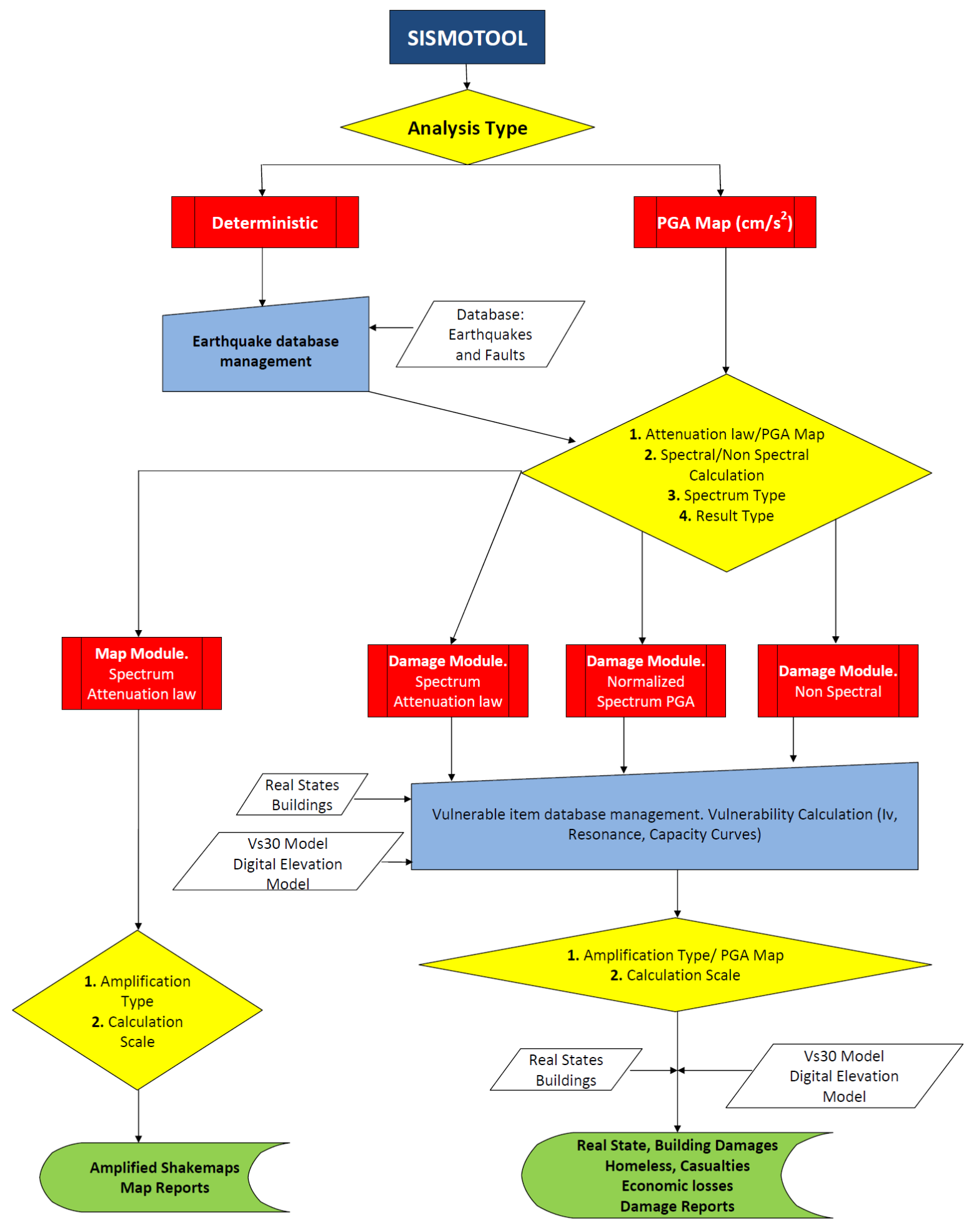

Fig. 2 SISMOTOOL flowchart 

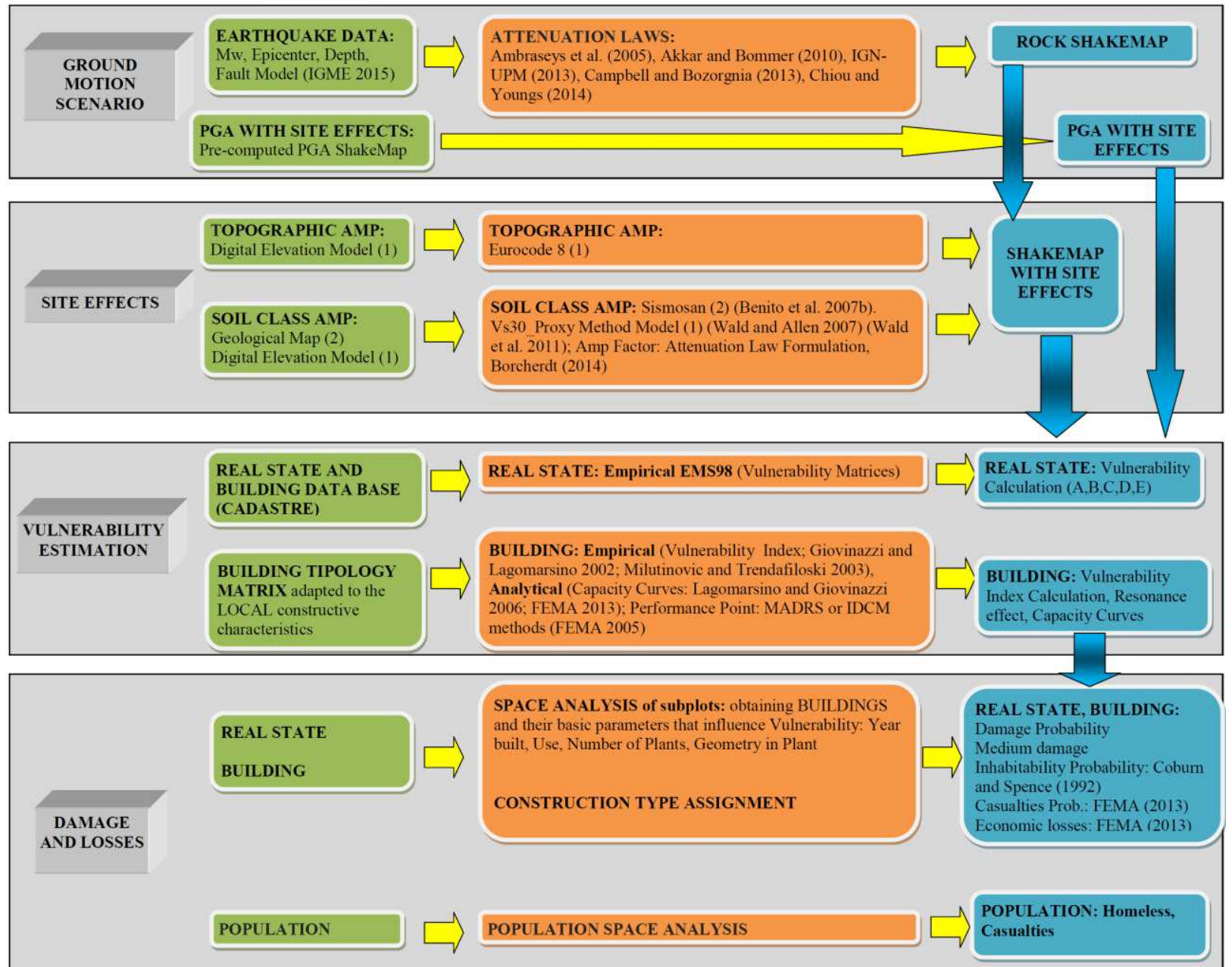

Fig. 3 SISMOTOOL development and computation scheme

Although the methodology could be understood easily at a glance from figures, some procedures, specially developed or coded in SISMOTOOL, are highlighted below:

\subsubsection{Ground motion scenarios}

The first step in any ELE computation is the description of the seismic impact in terms of shakemap; of course, this description must cover the region where the losses want to be determined. To do that, SISMOTOOL implements two options: first one is the deterministic scenario and the second choice is the pre-computed shakemap.

In the first option, the user can select the source parameters for a given earthquake (moment magnitude, latitude and longitude of the epicentre, focal depth or

174 faulting type) from a pre-defined database of historical earthquakes. Additionally, a 
proprietary fault DB based on QAFI (Quaternary active faults DB of Iberia, IGME 2015) is integrated into the program. SISMOTOOL draws the horizontal projection of the rectangles that represent the basic geometry of the faults and stores all the parameters obtained from QAFI (Fig. 4). Therefore, the user can simulate any possible earthquake related to any of these faults and SISMOTOOL will estimate the Rupture Area using moment magnitude and the relationship given by Wells and Coppersmith (1994).

181 Obviously, the Rupture Area is spatially located in a plane parallel to the chosen fault plane and centered on the Hypocenter which can be defined by the user through the epicentral coordinates and the focal depth; however, if depth is unknown, this parameter will be automatically computed by SISMOTOOL as the intersection of the fault plane with the vertical line from the epicenter, as well as, a boundary condition is applied assuming that rupture area calculated before cannot get out from the earth's surface (Fig. 5).

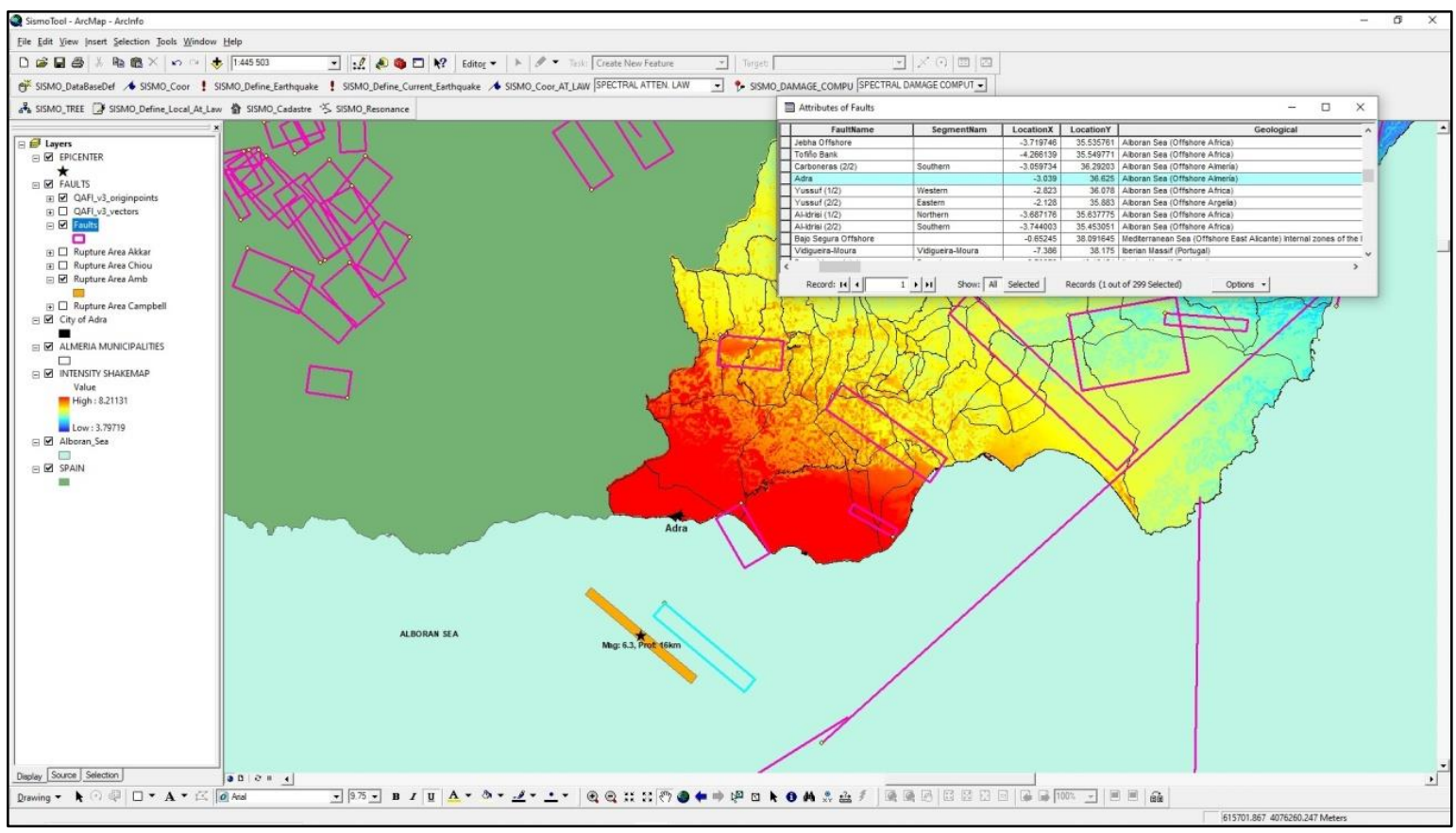


Fig. 5 SISMOTOOL generation scheme of the rupture area and focal depth computation

204

205

Next, the shakemap in terms of PGA at rock is computed after the selection of an appropriate ground motion prediction equation (GMPE). SISMOTOOL allows the user choosing between several GMPE currently implemented in the code. In particular, there are two European GMPE (Akkar and Bommer 2010 and Ambraseys et al. 2005) which are also suitable to Spain (IGN-UPM 2013); one Spanish GMPE (IGN-UPM 2013) valid for $M_{w}$ $<5.0$ and two of the latest Next Generation Attenuation (NGA) (Campbell and Bozorgnia 2013 and Chiou and Youngs 2014) which can be applied worldwide and considers also the directivity and directionality of the source. Additionally, the user can easily modify the Spanish GMPE by changing its coefficient.

It is well known that one of the main sources of uncertainties comes from the GMPE chosen; thus, the user has to decide what model, or combination of models, are appropriate. Bommer and Stafford (2020) pointed out that the emphasis in the choice of GMPEs should be focused on their amenability to the target region and site instead of on the basis of their applicability. This difficulty has been taken into account and section 3 will show how SISMOTOOL can help to decide the corresponding GMPE by comparing the results with previously recorded earthquakes according to PGA.

The results can be expressed in terms of specific or design response spectrum (5\% damped) following Eurocode 8 (CEN 2004a) guidelines. 
(2) Pre-computed shakemap

In the second option, the user can upload a PGA shakemap for the region in raster format including site effects, from which it is obtained an elastic response spectrum $(5 \%$ damped) according to Eurocode 8 (CEN 2004a).

\subsubsection{Site effects}

Two factors are analyzed by SISMOTOOL: Topographic Amplification and Soil Class Amplification.

(1) Topographic Amplification

SISMOTOOL has implemented a specific subroutine to arrange a topographic amplification file in raster format. The topographic amplification factor according to Eurocode 8 (CEN 2004b) methodology has values ranging from 1.0 (low) to 1.4 (high) and it is based on the slope angle. Therefore, a Digital Elevation Model (DEM) with resolution enough (at least, 5-10 m) is needed and then two basic parameters are extracted from the DEM (Fig. 6):

Height Relative to the Hydrographic Network $(H)$. The Hydrographic Network is obtained through the DEM using the Hydrology tool of the ArcGis Spatial Analyst. The compiled Hydrographic Network raster file is first converted to vector, then to lines and finally to points (FeatureVerticesToPoint tool). These points are transformed into an Inverse Distance Weighted (IDW) interpolation 3D surface (RasterInterpolation tool) using the heights of the DEM itself. Finally, the relative height of the ground with respect to that interpolation surface of the Hydrographic Network is calculated.

Slope Map evaluated as the most unfavorable of the following two options:

- The slope calculated at each point using the ArcGis Spatial Analyst Slope tool, on a raster file of the DEM. This function calculates the maximum elevation rate with respect to the distance, between each raster cell and its neighbor one.

- The average slope from the nearest free field of reference (Hydrographic Network). To do this, the height $(\mathrm{H})$ relative to the Hydrographic Network is 


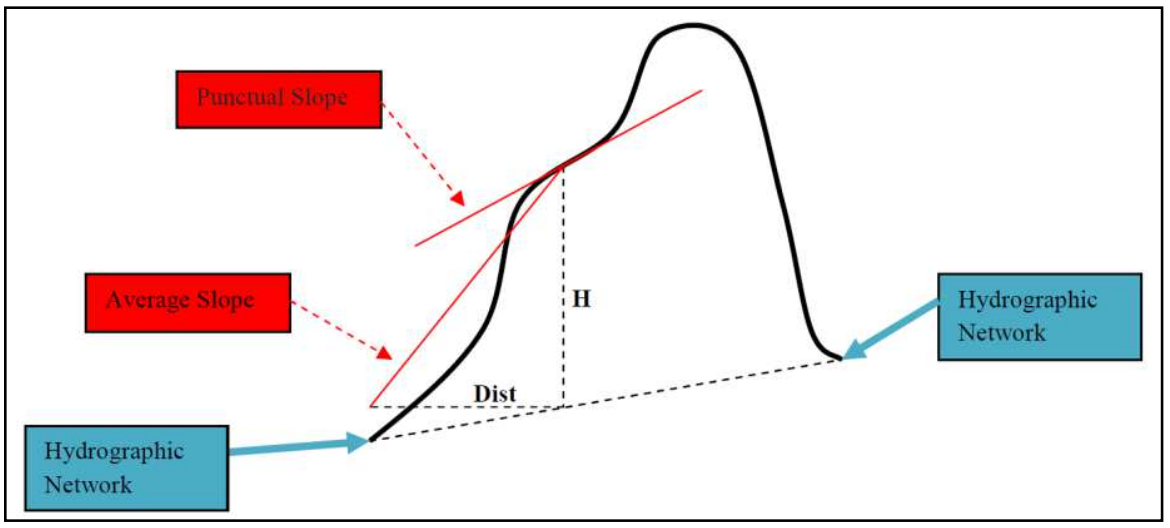

Fig. 6 Scheme of parameter extraction from the DEM needed to implement the topographic amplification according to Eurocode 8 (CEN 2004b)

for Almería province, centered on the municipality of Adra.

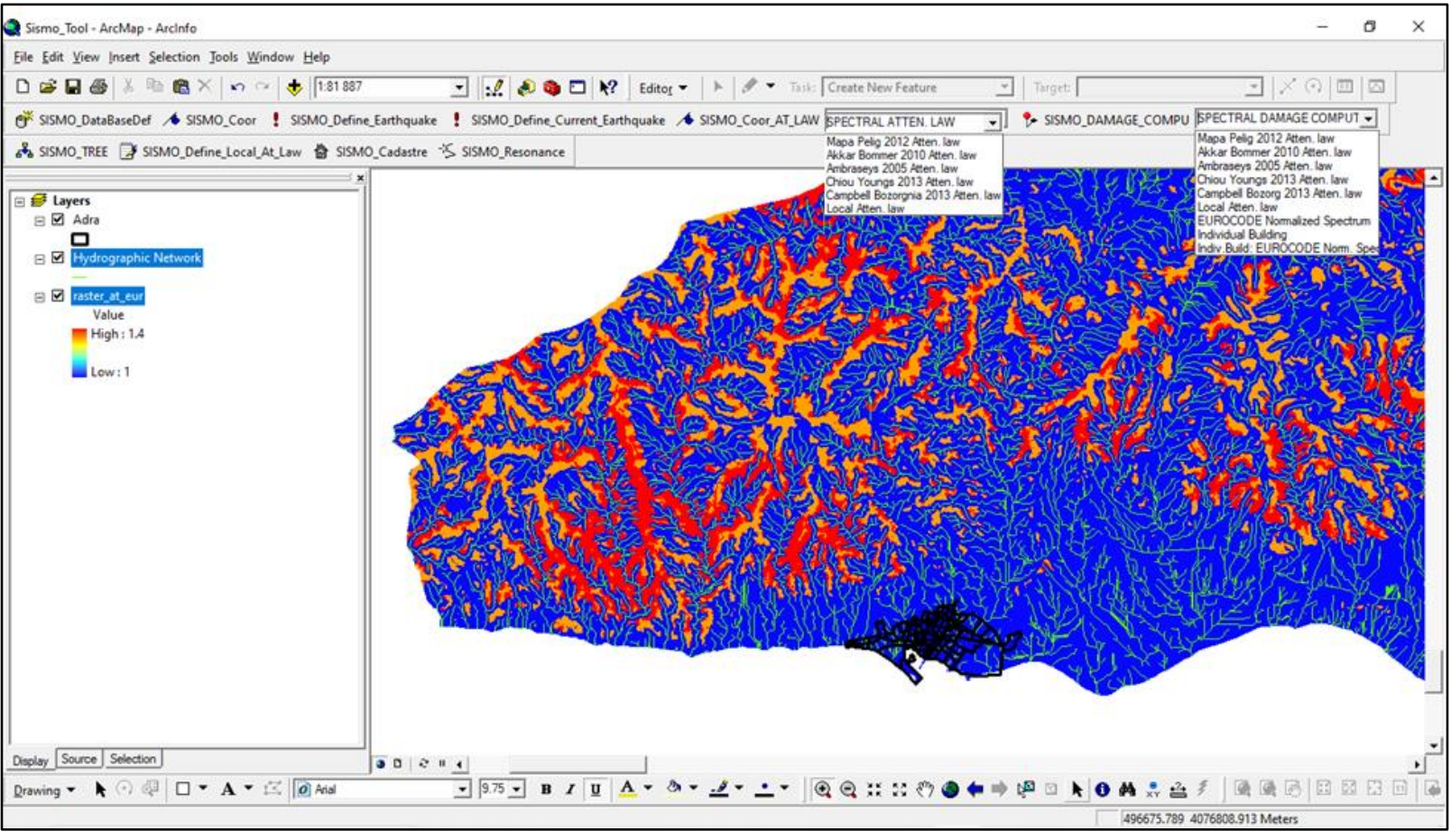

Fig. 7 Topographic amplifications according to Eurocode 8 (CEN 2004b) and Hydrographic Network, generated for Almería province, through a high-resolution DEM (10m). Map centered on the municipality of 
The soil characteristics are classified by SISMOTOOL using the mean shear-wave velocity in the uppermost $30 \mathrm{~m}$ ground thickness (Vs30). Initially, the user can select between an automatic estimation process of the Vs30 values distribution in the region by using the topographic slope as a proxy (Wald and Allen 2007) or it is possible to provide the geological map with its corresponding Vs30 values distribution map in raster format. Otherwise, the user can adopt specific correlations between the slope and Vs30 field observations with the aim to increase the accuracy of the Vs30 results using the topographic slope as a proxy. In this step, SISMOTOOL quantify equation (1) (Wald et al. 2011) to solve the shear-wave velocity coefficients $\left(\beta_{i}\right)$ for each geological unit:

$$
\log (V s 30)=\beta_{0}+\sum \beta_{i} \times x_{i}+\beta_{\text {slope }} \times \log (\text { slope })+\text { residual }
$$

where: $x_{i}$ are variables indicative of the geological units used in the model; $\beta_{i}, \beta_{\text {slope }}$, are 278 the coefficients to be calculated using the least squares regression; Vs30 is the instrumental shear-wave velocity values in $\mathrm{m} / \mathrm{s}$; and slope is the computed value from the DEM expressed in $\mathrm{m} / \mathrm{m}$, in order to carry out the regression.

An example of the application for Adra town is shown in Fig. 8. On one hand 282 Martínez-Pagán et al. (2018) calculated Vs30 values from the Spatial Autocorrelation (SPAC) passive method (Aki 1957) though ambient noise measurements, and the combined use of active and passive forms of the Multichannel Analysis of Surface Waves (MASW) method (Park and Miller 2008). On the other hand, IGME (1983) provided the geological units proposed in the Geological Map of Spain at a scale of 1:50000 (MAGNA_50). Figure 8a shows that if only the local relationship between the slope and the calculated Vs30 values is taking into account (Eq. 1) then the reliability using the 'Multiple R Squared (MRS)' is $72.1 \%$. Nevertheless, if the geological units are also considered on the correlation between the calculated average values of Vs30 and the slope (Eq. 1) the reliability increases up to $78 \%$ (Fig. 8b). Figure 9 compares the residuals 
correlation of Wald and Allen (2007), showing again as the lower residuals are obtained when equation (1) is used.

Therefore, if a map of Vs30 values is needed for a large territory, for example the entire municipality of Adra, then SISMOTOOL calculates it by using equation (1) in the territory defined by the geological units from which the sampling data are available, and the correlation only with the slopes (200 m resolution) for the territory outside those zones (Fig. 10).

a)

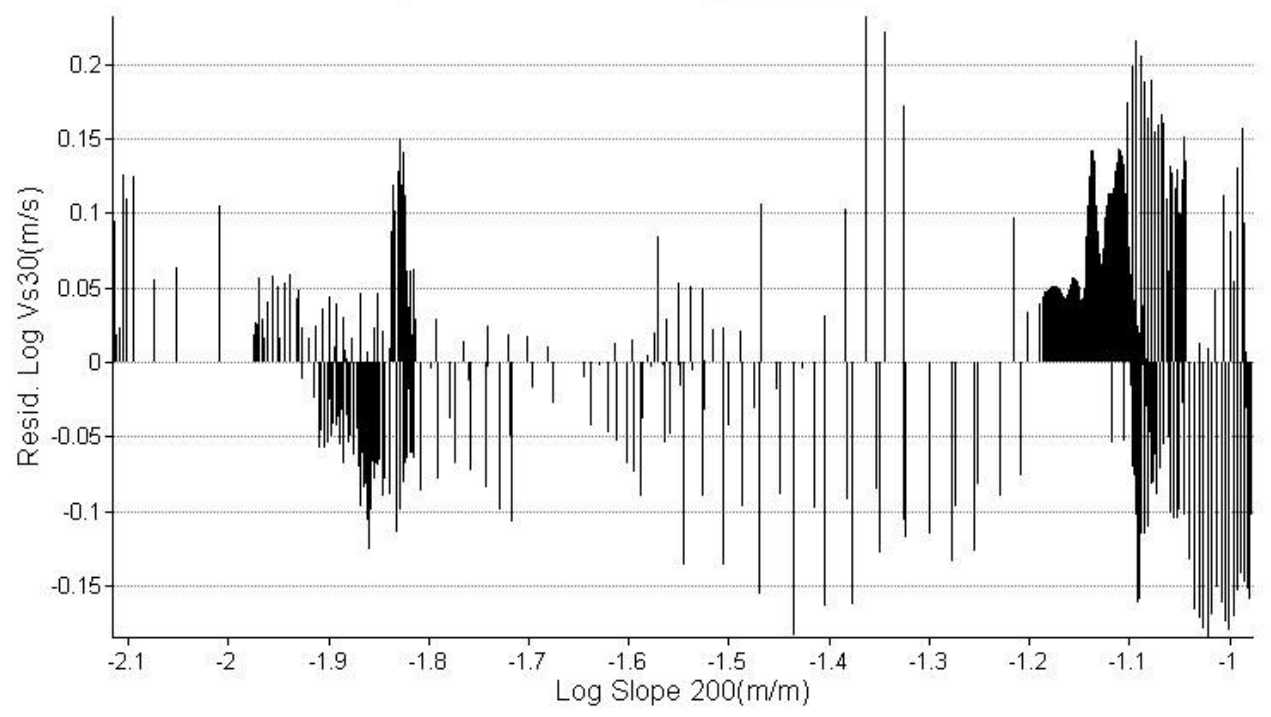

b)

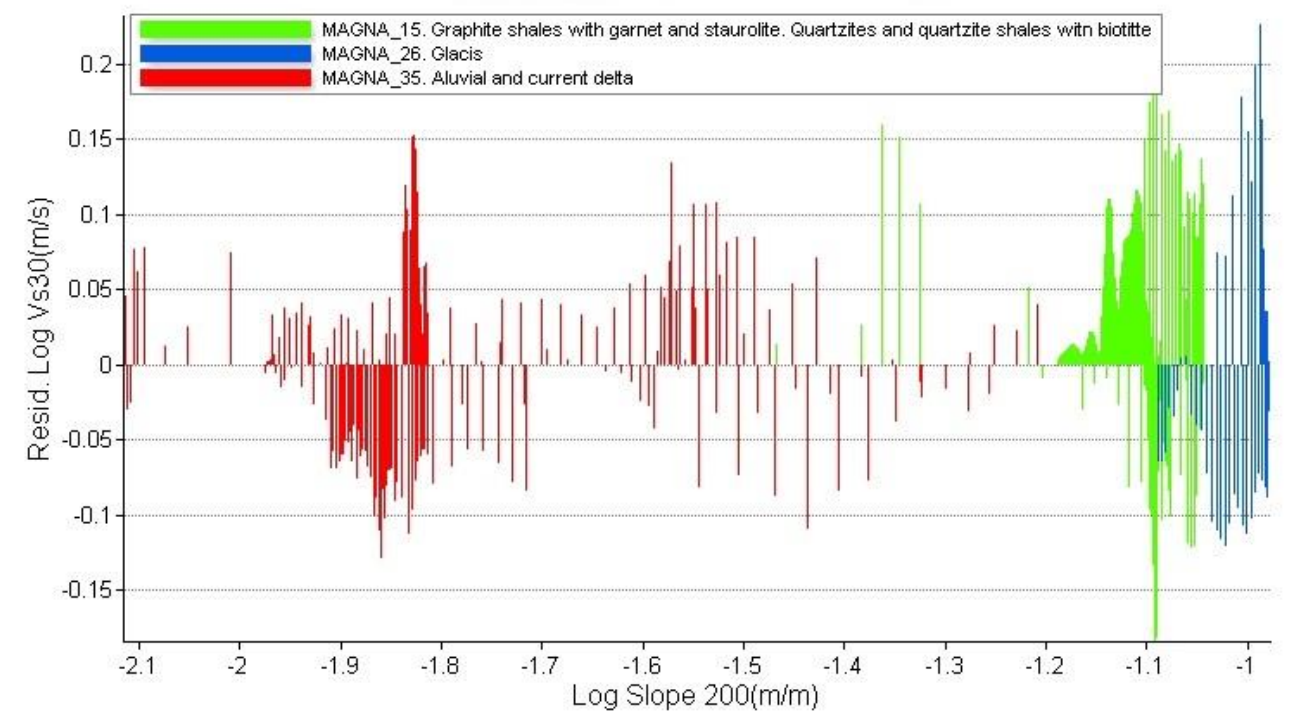

Fig. 8 Residuals of the correlation obtained between $\log (\mathrm{Vs} 30[\mathrm{~m} / \mathrm{s}])$ and $\log (\mathrm{Slope}[\mathrm{m} / \mathrm{m}])$ with a resolution of 200 m, for Adra town: a) using Vs30 and slope (MRS 72.1\%); b) using Vs30, slope and MAGNA_50 geological 


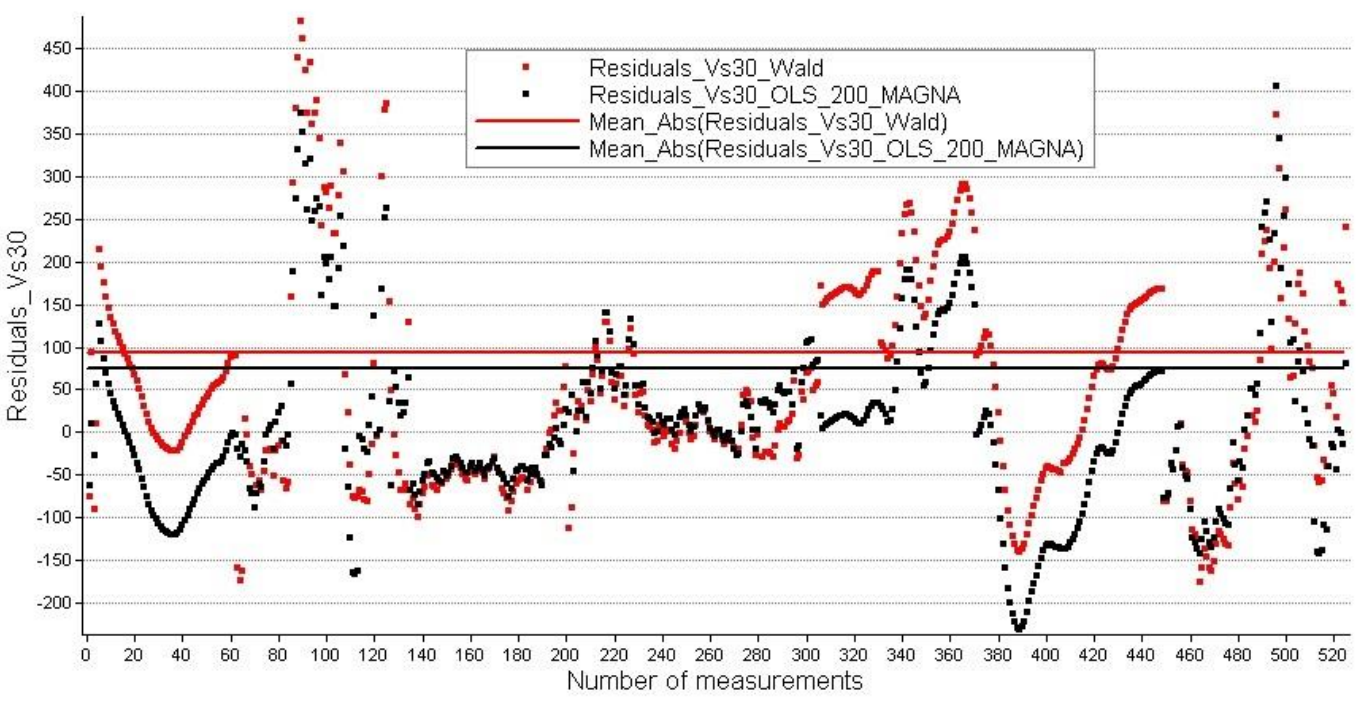

Fig. 9 Comparison of residuals at the sampling points, between the correlation obtained for $\log (\mathrm{Vs} 30[\mathrm{~m} / \mathrm{s}])$ in the city of Adra. Red points correspond to predicted values without using MAGNA_50 geological units and

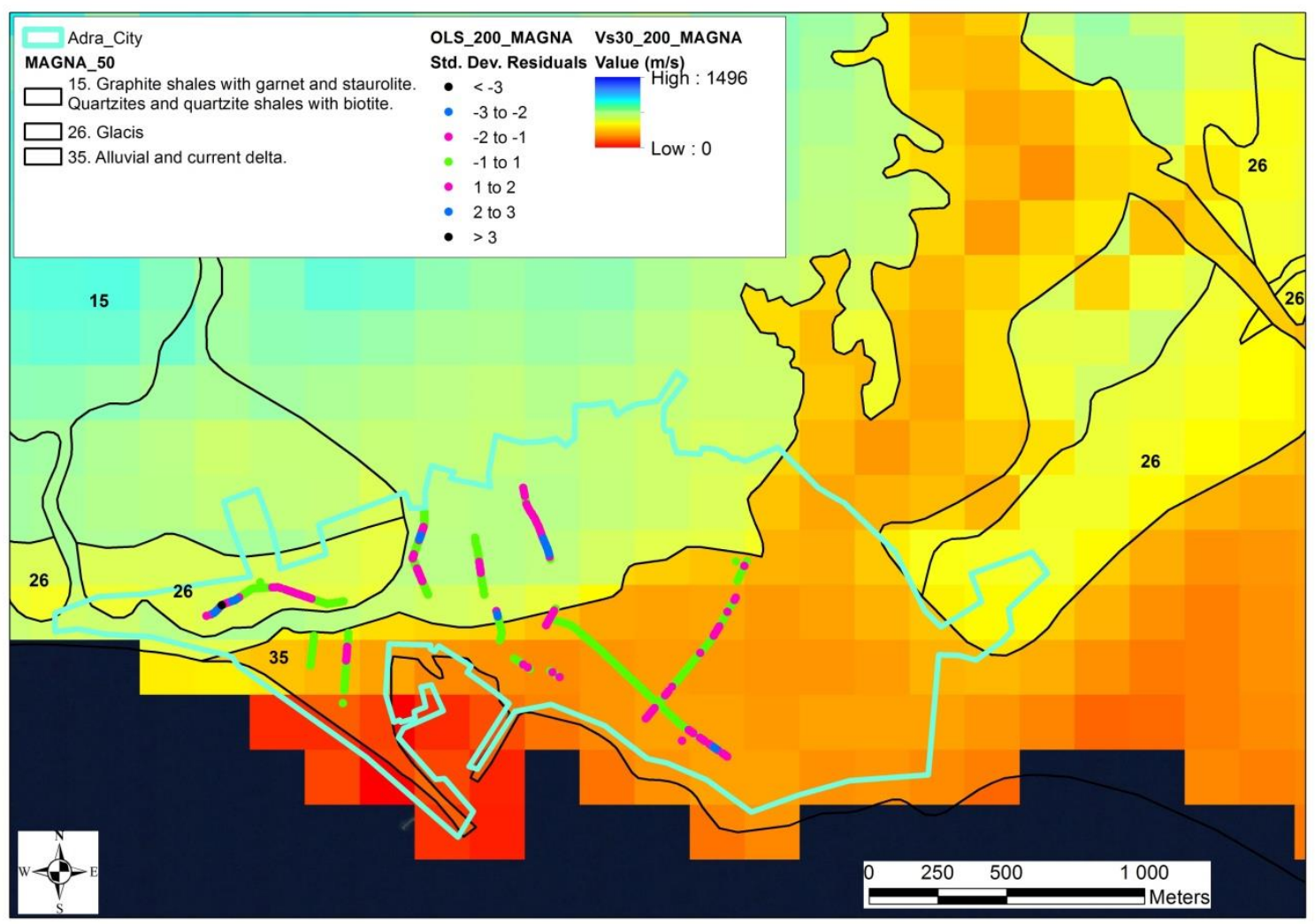

Fig. 10 Predicted Vs30 map of the municipality of Adra. The correlation using MAGNA_50 geological units

312 (MRS 78\%) is used for the sampling area and the correlation only with slopes (MRS 72.1\%) for the rest of the municipality. The Vs30 observations are represent as point with a different color according to the number of 

predicted Vs30 values from equation (1) for the urban area of Adra. As can be seen, the predicted values from SISMOTOOL are in agreement with the field measurements.

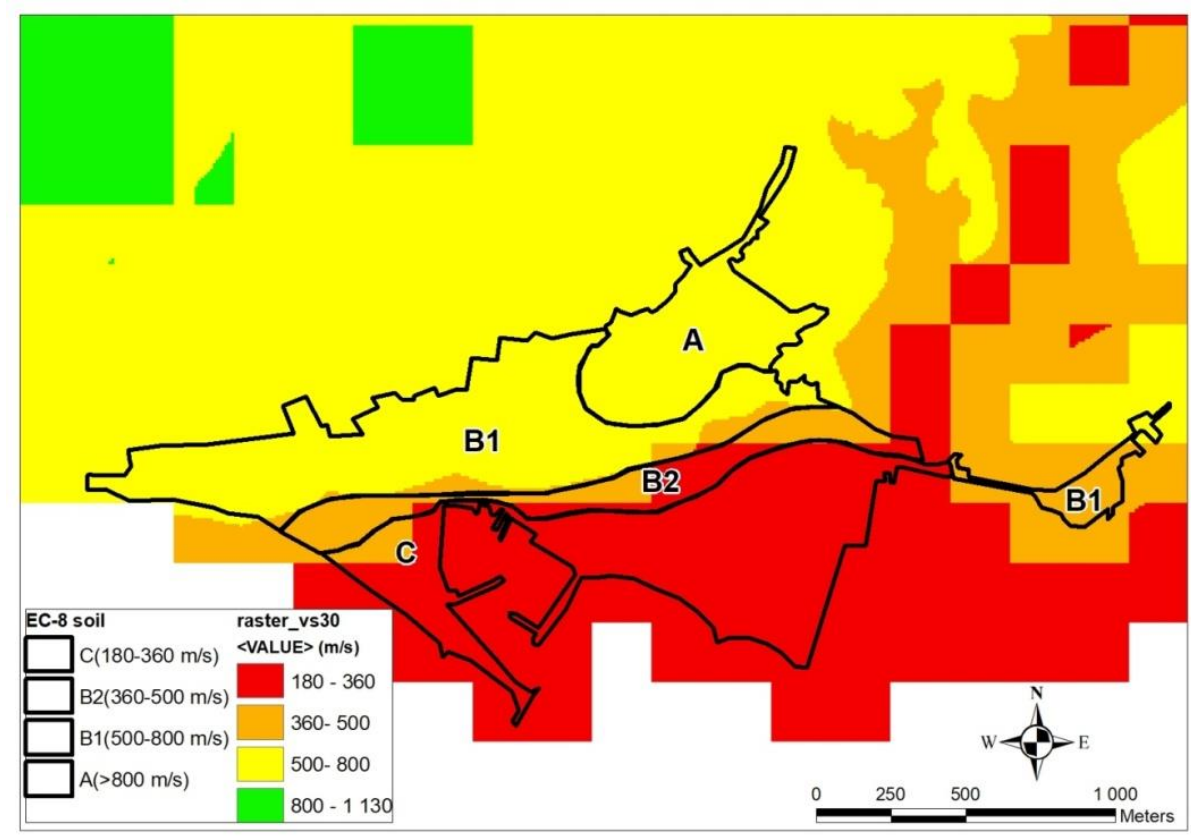

Fig. 11 Soil class comparison determined by the predicted Vs30 values proposed by SISMOTOOL using equation (1) and the field measurements proposed by Martínez-Pagán et al. (2015) (black contours), for the

In order to check the sensitivity of the Vs30 correlations to the slope map resolution, equation (1) has been fitted using a slope map with three different resolutions: $200 \mathrm{~m}, 100 \mathrm{~m}$ and $10 \mathrm{~m}$. In Figure 12 the slope map resolution shows a strong influence on the results: the correlation decreases from a MRS equal to $72.1 \%$ for a $200 \mathrm{~m}$ slope resolution map (Fig. 12a) to a MRS equal to $69.2 \%$ for a $100 \mathrm{~m}$ resolution (Fig. 12b) and, finally, to a MRS equal to $61.2 \%$ for a $10 \mathrm{~m}$ slope resolution map (Fig. 12c). Due to these results, it is concluded that the use of a $10 \mathrm{~m}$ slope resolution map is not appropriated, possibly due to the fact that these more precise scales show abrupt variations in slopes that are not reflected in the soil geomorphology. 


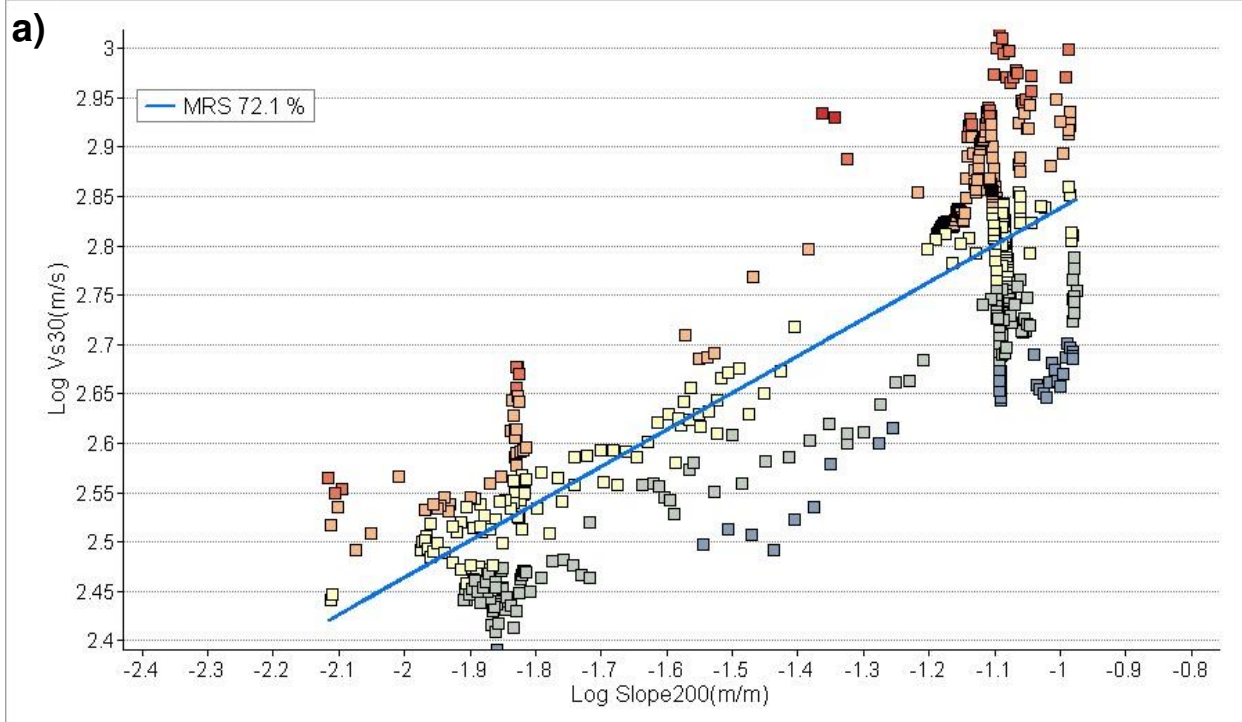

b)

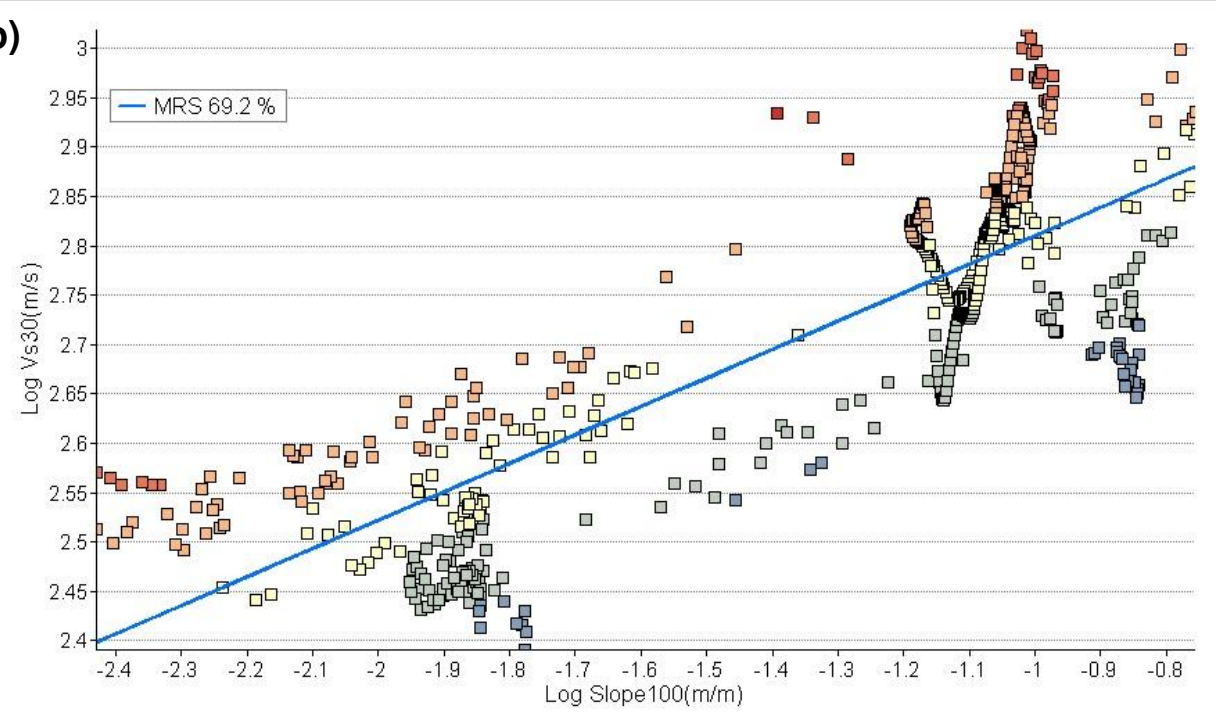

c)

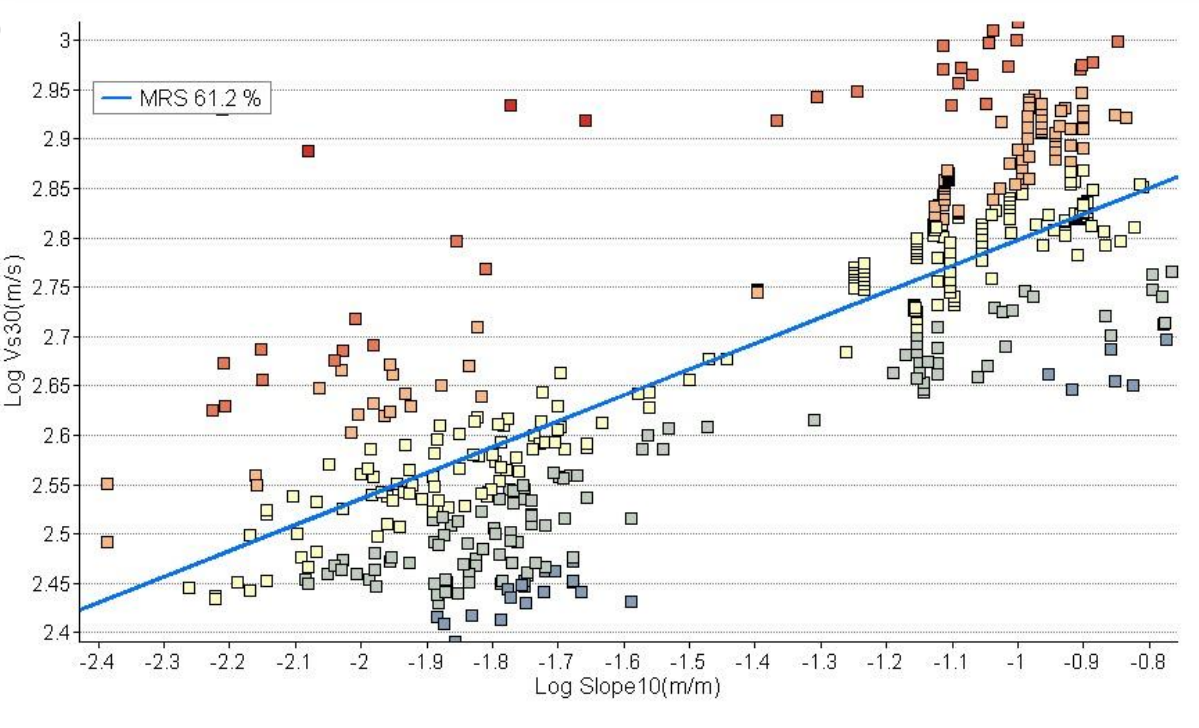

337 Fig. 12 Correlation obtained between $\log (\mathrm{Vs} 30[\mathrm{~m} / \mathrm{s}])$ and $\log (\mathrm{Slope}[\mathrm{m} / \mathrm{m}])$, for Adra town using different slope 
340 rock obtained in section 2.2.1. The first method (M1) inserts the Vs30 values in the corresponding GMPE to compute the amplified ground motion. The second method (M2)

342 uses the relationship between Vs30 values and the corresponding amplification factors 343 given by Borcherdt $(1994,2014)$ to obtain the amplified ground motion.

Figure 13 shows an example of PGA amplification factor for the 1910 Adra earthquake scenario using the PGA from Ambraseys et al. (2005) GMPE and M2 soil class amplification method applied according to predicted Vs30 values from equation (1) using a slope map with 200 m resolution.

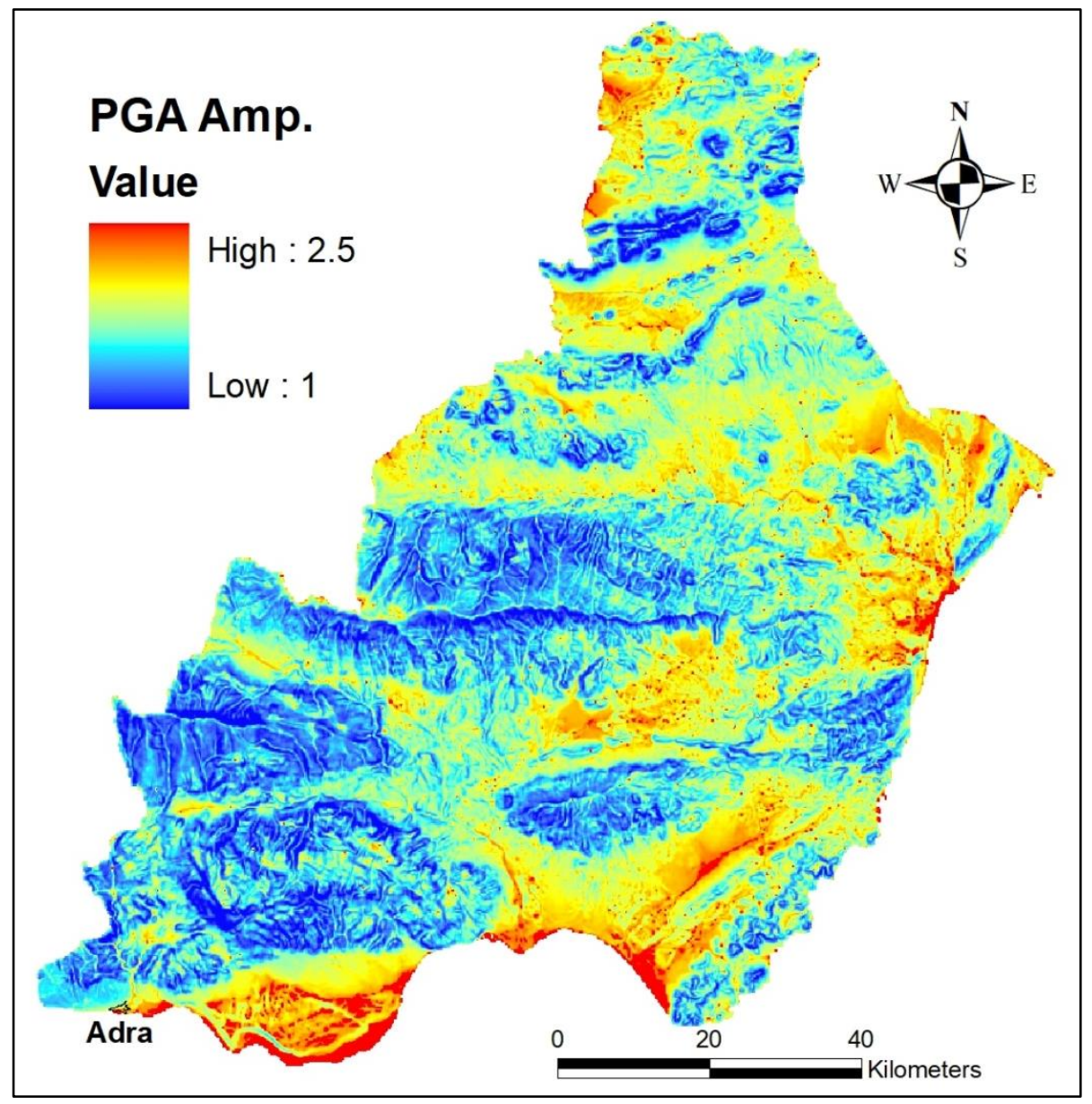

Fig. 13 PGA amplification factor for the Adra earthquake of 1910, obtained by SISMOTOOL for the Attenuation Law of Ambraseys et al. (2005) in rock; M2 soil class amplification method with Wald et al. (2011) proxy method to estimate Vs30 values (through the own correlation obtained with $200 \mathrm{~m}$ slopes resolution and 
As in the previous section, SISMOTOOL has specific tools to obtain Vs30 raster

356

357

358

359

360

361

362

363

364

365

366

367

368

369

370

371

372

373

374

375

376

377

378

379

maps of high resolution and amplified shakemaps. Therefore, the user can draw intensity, PGA and spectral acceleration maps with a pixel resolution of 5 to $10 \mathrm{~m}$ at different spatial scales (national, regional, local, user defined).

\subsubsection{Building database compilation}

From Civil Protection Services and stakeholder's point of view, one of the biggest difficulties arises in the vulnerability classification of a city (or region) and, above all, how to keep that information updated. To avoid this problem, SISMOTOOL incorporates an automatic extraction process from the "Dirección General del Catastro" internet server (SEC 2018), which is the Spanish agency in charge of the formation and maintenance of the Real Estate Cadastre as well as the dissemination of the cadastral information. From this source and through the new GML format of the cadastral database (European INSPIRE directive), polygonal elements can be obtained as urban subplots which represent the built volumes within a plot. They contain the needed information for vulnerability classification: geometry of the floor, height of the buildings, year of construction and rehabilitation or kind of occupation and state of preservation.

SISMOTOOL automatically processes this information to obtain the elements considered as buildings. In the first place, it filters the construction elements from the alphanumeric coding of subplots. For example, the coding -II + IV + TZA represents a subplot made up of floors from level -2 to level 4 and an additional terrace (SEC 2018). Subsequently, all the construction elements belonging to the same plot are joined, to form the building element (Fig. 14), and the maximum number of floors of each building (Fig. $15 a$ ) is extracted through an SQL selection algorithm (Fig. 15b). Finally, a topology rule is applied, with the help of the ArcGIS topology tools, to validate the geometry of the buildings: adjacent buildings must share both its linear and point limits. 

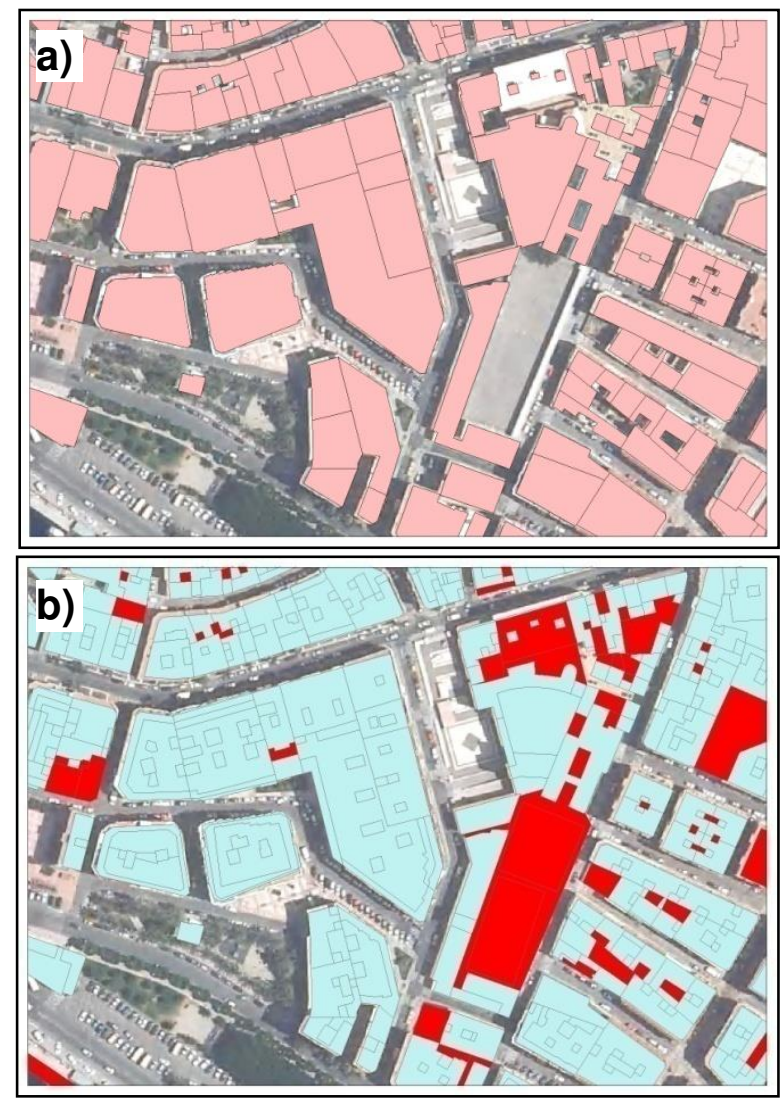

Fig. 14 Example of the result of automatic building floor extraction (a) from the constructive elements (b)
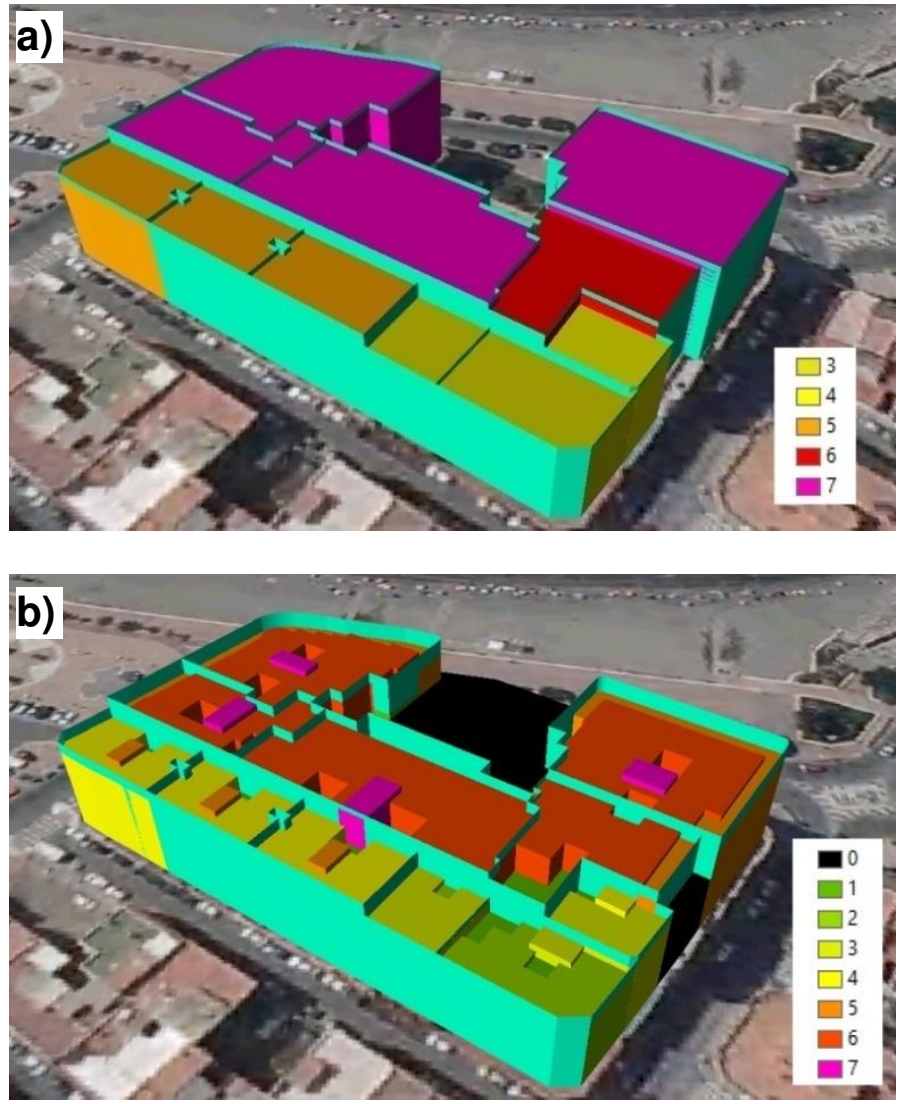

Fig. 15 Example of the maximum number of floors extraction process (a) from the constructive elements (b) 
Once the building database was compiled (section 2.2.3), the user can directly define the vulnerability of the buildings. Normally, this is not possible due to the lack of 390 information on construction typologies, and it is necessary to make a statistical assignment of the vulnerability through a Building Typology Matrix (BTM, Table 2). SISMOTOOL incorporate a default BTM adapted to local construction characteristics, and based on available basic data such as the year of construction and the number of floors. Then, it is possible to assign (always as a pre-process) the vulnerability of each building based on the probability of belonging to each typology $\left(\operatorname{Pr}\left(\operatorname{Typolog} y_{i}\right)\right)$ and the vulnerabilities defined for each basic typology (Vul_Typologyi) (Eq. 2):

$$
\text { Vul_Building }=\sum_{\text {Typology_i } \mathrm{i}} \text { Vul_Typology }_{\mathrm{i}} \times \operatorname{Pr}\left(\text { Typology }_{\mathrm{i}}\right)
$$

SISMOTOOL allows the user to define a specific BTM through a form containing the information shown in Table 2. For example, Molina et al. (2018) obtained a BTM for Adra town, based on cadastral information, previous research projects and random field trips around the city. They assigned a specific typology and vulnerability to each of the buildings (Table 2). This is the default BTM included in SISMOTOOL (which will be later used in sections 3 and 4 to validate the results).

With respect to the vulnerability modifiers, which do not depend exclusively on geometric parameters, they can be changed in the BTM. The vulnerability modifiers are needed in the empirical method (Giovinazzi and Lagomarsino 2002) because the vulnerability of a building is obtained through a vulnerability index $(I v)$; this index

408 (Iv Building $)$ is computed once the vulnerability index of the basic typology (IVtypology $)$ is 409 calculated, the modifiers according to the location (regional modifier $\Delta M_{R}$ ) are applied and 410 the modifiers related with structural typology, position in a block, irregularities, seismic design level or soft story have taken into account (behavior modifiers $M b_{j}$ ) (Eq. 3). 


$$
I v_{\text {Building }}=I v_{\text {typology }}+\Delta M_{R}+\sum_{j=1}^{n} M b_{j}
$$
and height) of each building as well as its relationship with the contiguous buildings.

417 SISMOTOOL access to this information by analyzing the basic geometry of each building
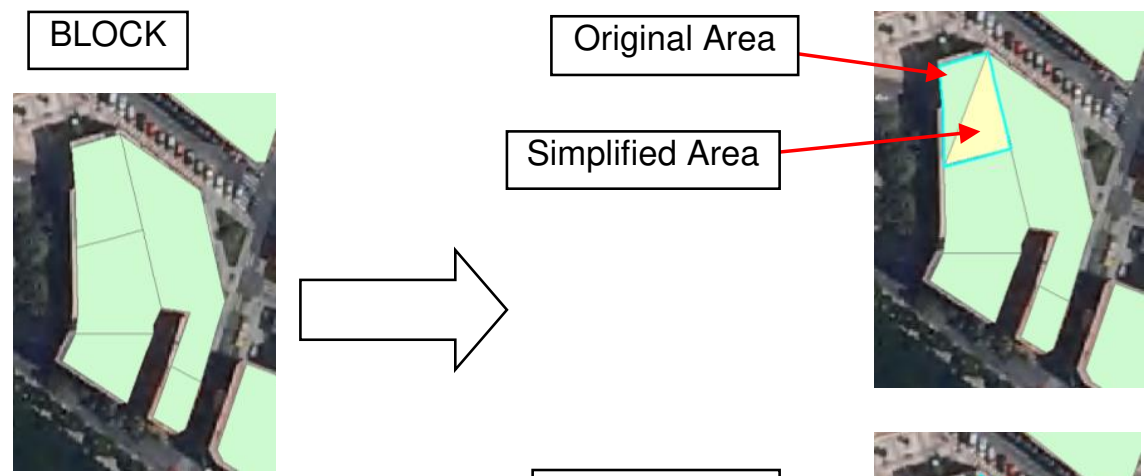

CORNER

BUILDING

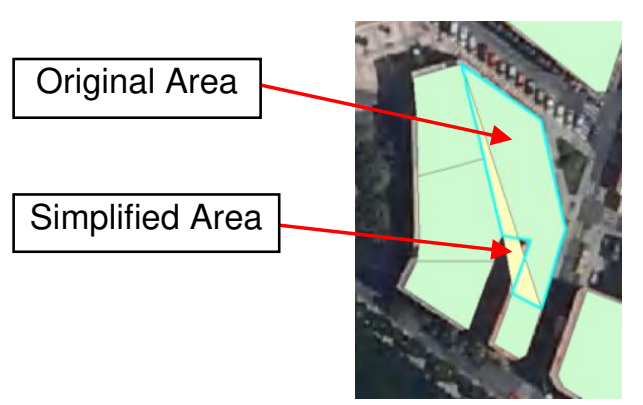

EXTREME BUILDING

Table 2 Example of a Building Typology Matrix for Adra town (obtained from Molina et al. 2018). The user can design a specific database changing the values of any of the fields of the table

\begin{tabular}{|c|c|c|c|c|c|c|c|}
\hline YEARS & FLOORS & PERCENTAGE & $\begin{array}{l}\text { BUILDING } \\
\text { TYPOLOGY }\end{array}$ & $\begin{array}{l}\text { TYPOLOGY } \\
\text { DESCRIPTION } \\
\text { Lagomarsino and } \\
\text { Giovinazzi }(2006)\end{array}$ & $\begin{array}{l}\text { REGIONAL Iv } \\
\text { MODIFIER }\end{array}$ & $\begin{array}{l}\text { CONSERVATION } \\
\text { Iv MODIFIER }\end{array}$ & $\begin{array}{l}\text { FLOORS Iv } \\
\text { MODIFIER }\end{array}$ \\
\hline \multirow{3}{*}{$\leq 1925$} & \multirow{2}{*}{$1-2$} & $25.3 \%$ & M2.w_L & $\begin{array}{l}\text { Adobe (earth bricks), } \\
\text { wood slabs, } 1-2 \text { floors }\end{array}$ & 0.14 & 0.04 & -0.02 \\
\hline & & $74.7 \%$ & M3.w_L & $\begin{array}{l}\text { Simple stone, wood } \\
\text { slabs, 1-2 floors }\end{array}$ & 0.14 & 0.04 & -0.02 \\
\hline & $3-5$ & $100 \%$ & M3.w_M & $\begin{array}{l}\text { Simple stone, wood } \\
\text { slabs, 3-5 floors }\end{array}$ & 0.14 & 0.04 & 0 \\
\hline$\leq 1945$ & $1-2$ & $72 \%$ & M5.w_L & Unreinforced Masonry & 0.12 & 0 & -0.04 \\
\hline
\end{tabular}




\begin{tabular}{|l|l|l|l|l|l|l|}
\hline & & & $\begin{array}{l}\text { (old bricks), wood } \\
\text { slabs, 1-2 floors }\end{array}$ & 0 \\
\cline { 3 - 7 } & $28 \%$ & M6_L_PC & $\begin{array}{l}\text { Unreinforced Masonry, } \\
\text { reinforced concrete } \\
\text { floors, 1-2 floors, Pre- } \\
\text { code seismic standards }\end{array}$ & 0.12 & -0.04 \\
\cline { 2 - 7 } & $100 \%$ & M6_M_PC & $\begin{array}{l}\text { Unreinforced Masonry, } \\
\text { reinforced concrete } \\
\text { floors, 3-5 floors, Pre- } \\
\text { code seismic standards }\end{array}$ & 0.12 & 0 \\
\hline
\end{tabular}

$438 \quad 2.2 .5$ Vulnerability modifier due to resonance soil-structure

439 The resonance effect between the soil and the structures occurs when the soil 440 predominant period coincides with the natural period of the existing building. It is well 441 known that this effect can have severe influence both on the degree and also on the 442 spatial distribution of building damage (even for moderate earthquakes). Recent examples 443 were observed in Spain, e.g. in 1993 and 1994 Adra earthquakes (Navarro et al. 2004, 444 2007) or in 1999 Mula earthquake (Navarro et al. 2000; García-Jerez et al. 2007).

SISMOTOOL computes a resonance probability map after the application of equations (4) and (5). The resonance probability is 1 if the predominant period of the soil $\left(T_{0}\right)$ and the natural period of the structure $\left(T_{b}\right)$ are equal and it decreases as the difference between the periods increase.

$$
\operatorname{Pr}(\text { Resonance })_{i}=1-A b\left(\frac{T_{0}-T_{b_{-} i}}{\operatorname{Max}\left(T_{0}, T_{b_{-} i}\right)}\right)
$$

$$
\operatorname{Pr}(\text { Resonance })=\sum_{\text {Typology_i }} \operatorname{Pr}(\text { Resonance })_{i} \times \operatorname{Pr}\left(\text { Typology }_{\mathrm{i}}\right)
$$

452 from the empirical relationship $T_{b}=a N$, where $N$ represents the number of stories and $a$ 453 is a constant which depends on the building typology (Navarro et al. 2007; Oliveira and 454 Navarro 2010; Gallipoli et al. 2010; Vidal et al. 2014, amongst others). Therefore, 455 SISMOTOOL incorporates a default Resonance Typology Matrix (RTM) (Table 3) 456 containing the a-value (named floors constant) and a resonance modifier (Mod_Iv_Resi) 457 corresponding to each building typology (Molina et al. 2018). This RTM will be used later 458 to compute a resonance modifier (Eq. 6) which can be combined with the others modifiers 459 in the empirical method. The user can also modify this RTM to adapt it to any study 
known.

462

$$
\text { Mod_Iv_Res }=\sum_{\text {Typology_i }}\left[\operatorname{Pr}(\operatorname{Resonance})_{i} \times \text { Mod_IV_Res }_{\mathrm{i}}\right]
$$

464 raster map in the urban area of Adra is plotted. This map is computed by spatial IDW 465 interpolation of the measurements carried out by Navarro et al. (2007) from ambient noise 466 HVSR; then, this raster and the relationship $T_{b}=0.049 \mathrm{~N}$ (Navarro et al. 2007) for 467 Reinforced Concrete buildings in Adra town, serve as a foundation to SISMOTOOL to compute the probability of resonance. Afterwards, buildings with a probability greater than $90 \%$ are plotted as red filled polygons.

470

Table 3 Example of Resonance Typology Matrix (RTM)

\begin{tabular}{|c|c|c|c|c|c|c|}
\hline YEARS & FLOORS & PERCENTAGE & $\begin{array}{l}\text { BUILDING } \\
\text { TYPOLOGY }\end{array}$ & $\begin{array}{l}\text { TYPOLOGY DESCRIPTION } \\
\text { Lagomarsino and Giovinazzi (2006) }\end{array}$ & $\begin{array}{l}\text { RESONANCE } \\
\text { Iv MODIFIER } \\
\text { (Mod_Iv_Res_i) }\end{array}$ & $\begin{array}{l}\text { FLOORS } \\
\text { CONSTANT }\end{array}$ \\
\hline \multirow{4}{*}{$\begin{array}{l}\geq 1977 \\
\leq 1996\end{array}$} & $1-3$ & $100 \%$ & RC1_III_L_DCL & $\begin{array}{l}\text { Concrete Moment Frame, 1-3 floors, } \\
\text { seismic code with seismicity zone III, } \\
\text { Low ductility capacity }\end{array}$ & 0.06 & 0.049 \\
\hline & \multirow{2}{*}{$4-7$} & $66.2 \%$ & RC1_III_M_DCL & $\begin{array}{l}\text { Concrete Moment Frame, 4-7 floors, } \\
\text { seismic code with seismicity zone III, } \\
\text { Low ductility capacity }\end{array}$ & 0.06 & 0.049 \\
\hline & & $33.8 \%$ & RC3_III_M_DCL & $\begin{array}{l}\text { Reinforced concrete Dual System, } 4-7 \\
\text { floors, seismic code with seismicity } \\
\text { zone III, Low ductility capacity }\end{array}$ & 0.06 & 0.049 \\
\hline & $\geq 8$ & $100 \%$ & RC3_III_H_DCL & $\begin{array}{l}\text { Reinforced concrete Dual System, } \geq 8 \\
\text { floors, seismic code with seismicity } \\
\text { zone III, Low ductility capacity }\end{array}$ & 0.06 & 0.049 \\
\hline \multirow{6}{*}{$\leq 2004$} & \multirow{2}{*}{$1-3$} & $2.8 \%$ & RC1_II_L_DCM & $\begin{array}{l}\text { Concrete Moment Frame, 1-3 floors, } \\
\text { seismic code with seismicity zone II, } \\
\text { Medium ductility capacity }\end{array}$ & 0.06 & 0.049 \\
\hline & & $97.2 \%$ & RC3_II_L_DCM & $\begin{array}{l}\text { Concrete Moment Frame, 4-7 floors, } \\
\text { seismic code with seismicity zone II, } \\
\text { Medium ductility capacity }\end{array}$ & 0.06 & 0.049 \\
\hline & \multirow{2}{*}{$4-7$} & $34.4 \%$ & RC1_II_M_DCM & $\begin{array}{l}\text { Concrete Moment Frame, } \geq 8 \text { floors, } \\
\text { seismic code with seismicity zone II, } \\
\text { Medium ductility capacity }\end{array}$ & 0.06 & 0.049 \\
\hline & & $65.6 \%$ & RC3_II_M_DCM & $\begin{array}{l}\text { Reinforced concrete Dual System, 1-3 } \\
\text { floors, seismic code with seismicity } \\
\text { zone II, Medium ductility capacity }\end{array}$ & 0.06 & 0.049 \\
\hline & \multirow{2}{*}{$\geq 8$} & $40 \%$ & RC1_II_H_DCM & $\begin{array}{l}\text { Reinforced concrete Dual System, } 4-7 \\
\text { floors, seismic code with seismicity } \\
\text { zone II, Medium ductility capacity }\end{array}$ & 0.06 & 0.049 \\
\hline & & $60 \%$ & RC3_II_H_DCM & $\begin{array}{l}\text { Reinforced concrete Dual System, } \geq 8 \\
\text { floors, seismic code with seismicity } \\
\text { zone II, Medium ductility capacity }\end{array}$ & 0.06 & 0.049 \\
\hline
\end{tabular}




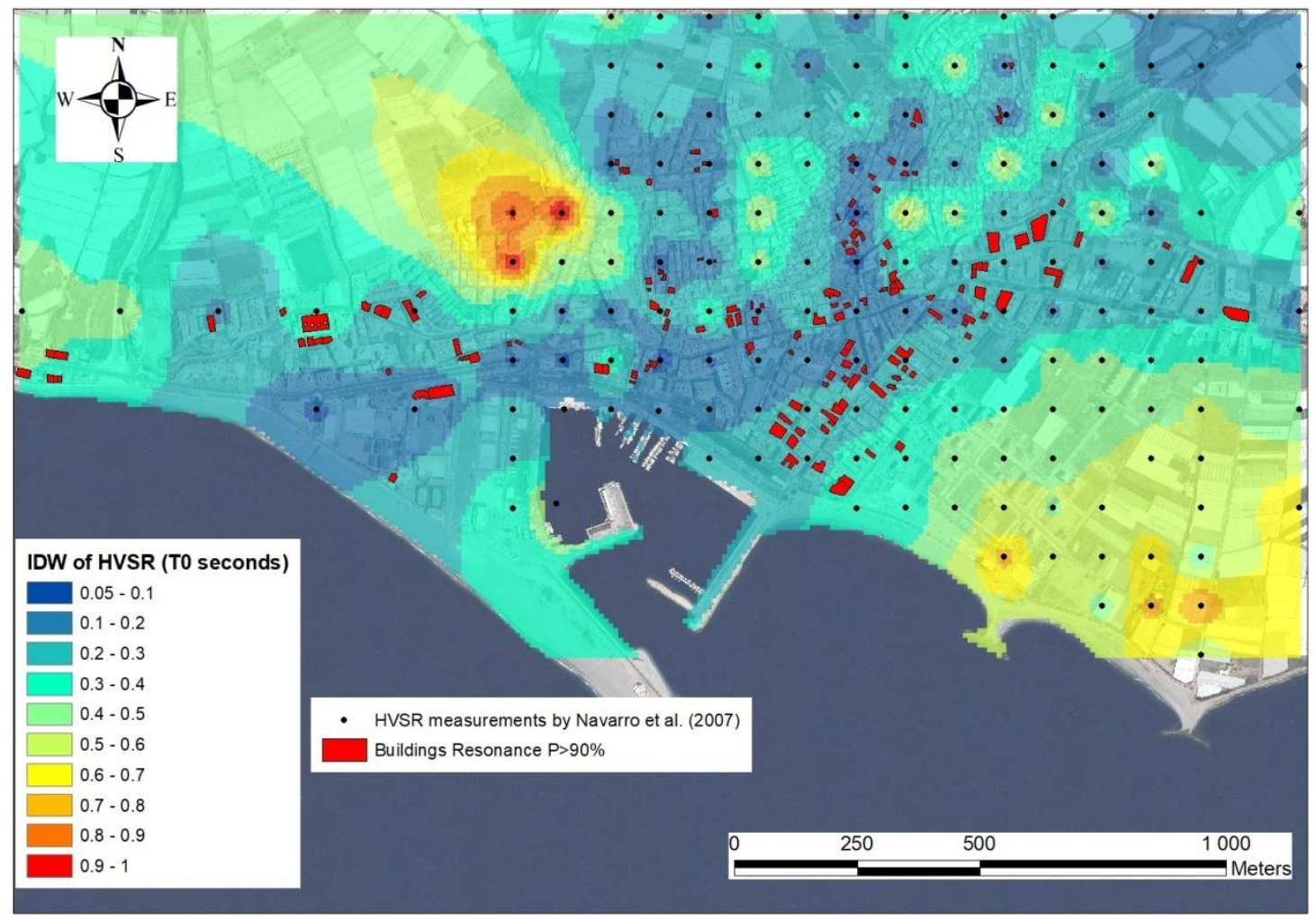

Fig. 17 Soil predominant period distribution map in Adra town

\subsubsection{Damages and Losses computation}

SISMOTOOL implements two ways to compute damages and losses; first one is empirical and the second one is analytical.

(1) Empirical Methodology (Vulnerability Index)

This methodology was proposed by Giovinazzi and Lagomarsino (2002) and described by Milutinovic and Trendafiloski (2003); these authors correlate the mean damage grade $\left(\mu_{D}\right)$, the macroseismic intensity ( $I$, calculated at the centroid of the polygon that represents the building) and the Vulnerability Index $\left(I_{V}\right)$ using semi-empirical vulnerability functions (Eq. 7):

$$
\mu_{D}=2.5\left[1+\tanh \left(\frac{I+6.25 I_{V}-13.1}{2.3}\right)\right]
$$

In other matters, the probability density function $p_{\beta}(x)$ on the continuous variable $x$ that defines the degree of damage to a building due to an earthquake can be modeled by the Beta distribution function (Eq. 8): 


$$
p_{\beta}(x)=\frac{\Gamma(t)}{\Gamma(r) \Gamma(t-r)} \frac{(x-a)^{r-1}(b-x)^{t-r-1}}{(b-a)^{t-1}}, a \leq x<b
$$

489

490

491

492

493

494

495

496

497

498

499

500

501

502

503

504

505

506

507

508

509

510

where: $a$ and $b$ represent the limits of the distribution function, and since the damage states in this case are six (null, slight, moderate, severe, extensive and collapse), therefore $a=0$ and $b=6$; $\Gamma$ is the Gamma function; and the parameter $r$ is correlated with the mean damage grade $\mu_{D}$ (Eq. 9):

$$
r=t\left(0.007 \mu_{D}^{3}-0.052 \mu_{D}^{2}+0.2875 \mu_{D}\right)
$$

being $t=8$ bias the dispersion of the distribution and is established so that the Beta distribution function would be similar to the Binomial distribution of $\mu_{D}$ (Giovinazzi and Lagomarsino 2002).

To perform these calculations, SISMOTOOL has two algorithms that have been efficiently tested, assuming the huge number of buildings in a given region (e.g. 252,196 for the province of Almería); these algorithms are:

- Calculation of the Gamma $(\Gamma)$ function and the corresponding PDF (Eq. 8).

- Calculation of the CDF: $P_{\beta}(x)=\int_{a}^{x} p_{\beta}(\epsilon) d \epsilon$ avoiding possible discontinuities (which will occur at the points defined by the parameter $r$ ) by using that the sum of all the probabilities of damage must be equal to 1 .

(2) Analytical Methodology (Capacity Spectrum)

SISMOTOOL gets the performance point of a building due to a horizontal force applied to the structure (Fig. 18), by implementing two simplified procedures: I-DCM and MADRS according to FEMA (2005). In both procedures it is necessary to obtain the points of intersection between the bilinear capacity curve and the response spectrum. Again, and given the possible high number of buildings to be analyzed, special emphasis is done on the calculation efficiency of the intersection algorithms, as shown in Appendix 1. 
511

512

\section{3}

514

515

516

517

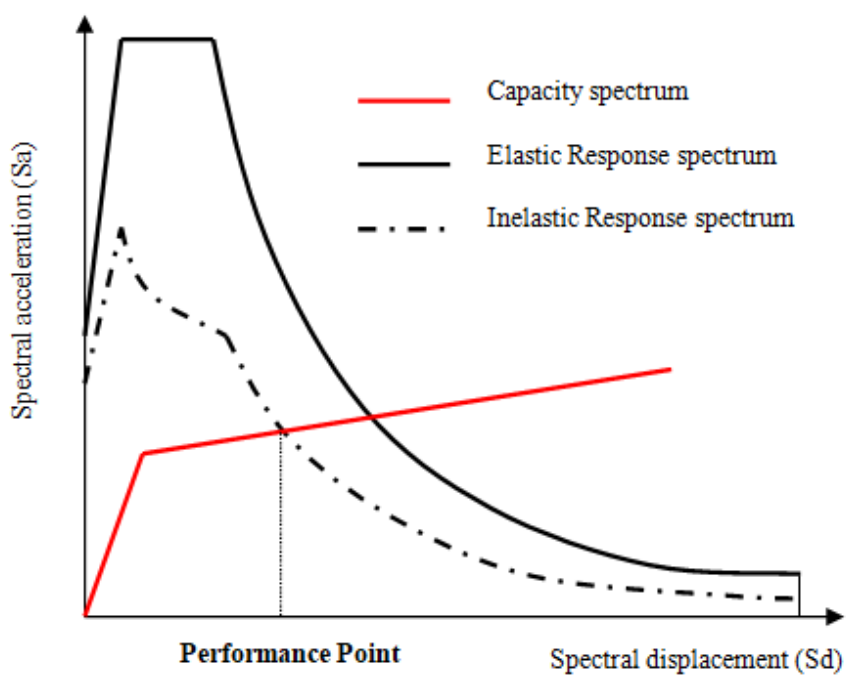

Fig. 18 Scheme for obtaining the Performance Point for analytical method (Capacity Curves)

After the performance point $(S d)$ is known, its value is used in the fragility curves to obtain the degree of damage (Slight, Moderate, Extensive and Complete) employing equation (10) (Milutinovic and Trendafiloski 2003):

$$
P[d s \mid S d]=\phi\left[\frac{1}{\beta_{d s}} \ln \left(\frac{S d}{S d_{d s}}\right)\right]
$$

518 where $P(d s \mid S d)$ is the probability that the damage state $d s$ is exceeded given $S d ; S d d s$ is

519 the mean value of the spectral displacement at which the structure reaches the damage state threshold $d s ; \beta_{d s}$ is the standard deviation of the natural logarithm of spectral displacement for damage state $d s ; \Phi$ is the standard normal cumulative distribution 522 function.

As an useful option, if the parameters $S d_{d s}$ and $\beta_{d s}$, which characterize the fragility curves, are not defined, SISMOTOOL can evaluate them:

- $\quad \boldsymbol{S d}_{\boldsymbol{d s}}$ obtained from the relations from Lagomarsino and Giovinazzi (2006), from the yielding $(D y)$ and the ultimate $(D u)$ displacements:

$$
S d 2=1.5 \text { Dy Moderate damage (Degree 2) }
$$

$$
S d 3=D y+0.5(D u+D y) \text { Extensive damage (Degree 3) }
$$



damage state in its mean spectral displacement is 0.5 , and the probability of the other damage states fits to the same Beta distribution used in the empirical methodology (Vulnerability Index). In this way, the discrete probability distribution is obtained, through the values of $\mu_{D}$ such that $P_{\beta}(x)=0.5$ for $x=1,2,3,4$. Table 4 shows the computed $\mu_{D}$ values, together with the probabilities that each damage state is exceeded (1$P_{\beta}(x)$, for $\left.x=1,2,3,4\right)$. Finally, a least squares adjustment of the Normal distribution $\Phi\left(\frac{1}{\beta_{d s}} \ln \left(\frac{S d}{S d_{d s}}\right)\right)$ is made to the values in Table 4, from which the standard deviation $\beta_{d s}$ is obtained. SISMOTOOL can perform this adjustment through a series of specifically designed algorithms.

542

543 Table $4 \mu \mathrm{D}$ values, such that the probability that the damage is less than or equal to the state of damage $\mathrm{x}$, is greater than or equal to 0.5 , along with the probabilities that each damage state will be exceeded

\begin{tabular}{|l|l|l|l|l|l|l|}
\hline $\begin{array}{l}\text { Damage } \\
\text { state }\end{array}$ & Hypothesis & $\mu \mathrm{D}$ & $1-\mathrm{P}_{\beta}(1)$ & $1-\mathrm{P}_{\beta}(2)$ & $1-\mathrm{P}_{\beta}(3)$ & $1-\mathrm{P}_{\beta}(4)$ \\
\hline Slight & $\mathrm{P}_{\beta 1}(1)=0.5$ & 0.911 & 0.5 & 0.119 & 0.012 & 0.000 \\
\hline Moderate & $\mathrm{P}_{\beta 2}(2)=0.5$ & 1.919 & 0.896 & 0.5 & 0.135 & 0.008 \\
\hline Extensive & $\mathrm{P}_{\beta 3}(3)=0.5$ & 3.081 & 0.992 & 0.866 & 0.5 & 0.104 \\
\hline Complete & $\mathrm{P}_{\beta 4}(4)=0.5$ & 4.089 & 1.000 & 0.988 & 0.881 & 0.5 \\
\hline
\end{tabular}
damage state, the residual function $\left(S_{d s}\right)$ with respect to the parameter $\beta_{d s}$ (for example, the process of fitting the Fragility curve for damage 1 or Slight is shown in Appendix 2). 
(3) Uninhabitable buildings and human losses

554

In relation with buildings, in both cases, empirical and analytical method, the

555

number of uninhabitable buildings is evaluated by equation (11):

556

$$
\text { Uninh }=\sum_{\text {Degree_i }} C_{i} \times \operatorname{Pr} \text { Degree_i }
$$

557

where $C_{i}$ are user defined coefficients. For example, Coburn and Spence (1992)

proposed: $C_{0}=C_{1}=0, C_{2}=0.5, C_{3}=0.9, C_{4}=C_{5}=1$

559

Otherwise, the human losses are computed following basically the HAZUS-MH

560 (FEMA 2013) approach (Eq. 12, 13):

561

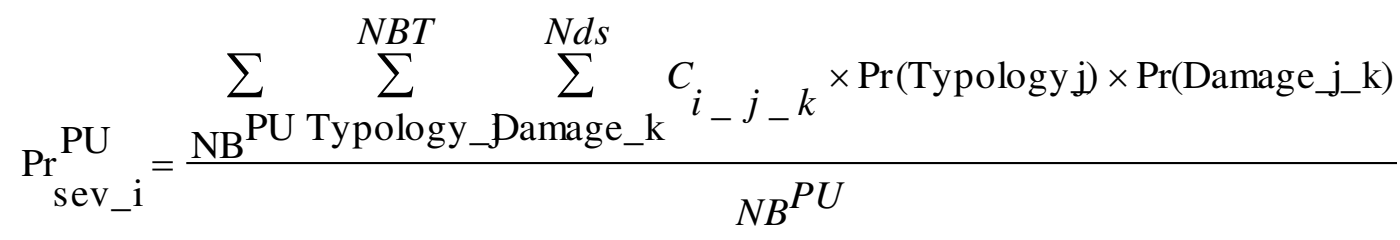

562

$$
\underset{\text { sev_i }}{P P_{-}^{P U}}=N P^{P U} \times \operatorname{Pr}^{P U}{ }_{S v_{-} i}
$$

563

where: $N B T$ is the number of building typologies; $N d s$ is the number of damage states

$(d s)$; $\operatorname{Pr}($ Typology_ $\mathrm{j})$ is the probability that a building belongs to typology $\mathrm{j}$;

$\operatorname{Pr}\left(\right.$ Damage $\left.\mathrm{j}_{-} \mathrm{k}\right)$ is the damage probability $k$ for a building of typology $j ; C_{i_{-} j_{-} k}$ is the casualty rate of severity $i$ for damage state $k$ for a building of typology $j$, provided by the user through a Human Loss coefficient matrix (HLCM) (Table 5); $\mathrm{NB}^{\mathrm{PU}}$ is the number of buildings in the population unit $\mathrm{PU} ; \mathrm{Pr}^{\mathrm{PU}}{ }_{\text {sev_i }}$ is the mean probability of casualty severity $i$

569 for population unit PU; $N P^{P U}$ is the number of people living in population unit $\mathrm{PU}$; and 570 finally, $N P^{P U_{\text {sev }} i}$ is the number of casualties with severity $i$ in population unit PU.

571 Severities are defined by HAZUS-MH (FEMA 2013) as Severity 1: Light injury, Severity 2:

572 Moderate injury, Severity 3: Severe injury and Severity 4: Fatal injury/death. 
2013) but they can be modified by the user

\begin{tabular}{|c|c|c|c|c|c|}
\hline $\begin{array}{l}\text { BUILDING } \\
\text { TYPOLOGY }\end{array}$ & $\begin{array}{l}\text { TYPOLOGY DESCRIPTION } \\
\text { Lagomarsino and Giovinazzi (2006) }\end{array}$ & $\begin{array}{l}\text { C_damage2 } \\
\text { Severity1 }\end{array}$ & $\begin{array}{l}\text { C_damage2 } \\
\text { _Severity2 }\end{array}$ & $\begin{array}{l}\text { C_damage2 } \\
\text { _Severity3 }\end{array}$ & $\begin{array}{l}\text { C_damage2 } \\
\text { _Severity4 }\end{array}$ \\
\hline M2.w_L & $\begin{array}{l}\text { Adobe (earth bricks), wood slabs, 1-2 } \\
\text { floors }\end{array}$ & 0.0035 & 0.004 & 0.00001 & 0.00001 \\
\hline M3.w_L & Simple stone, wood slabs, 1-2 floors & 0.0035 & 0.004 & 0.00001 & 0.00001 \\
\hline M3.w_M & Simple stone, wood slabs, 3-5 floors & 0.0035 & 0.004 & 0.00001 & 0.00001 \\
\hline M5.w_L & $\begin{array}{l}\text { Unreinforced Masonry (old bricks), } \\
\text { wood slabs, 1-2 floors }\end{array}$ & 0.0035 & 0.004 & 0.00001 & 0.00001 \\
\hline M6_L_PC & $\begin{array}{l}\text { Unreinforced Masonry, reinforced } \\
\text { concrete floors, } 1-2 \text { floors, Pre-code } \\
\text { seismic standards }\end{array}$ & 0.0035 & 0.004 & 0.00001 & 0.00001 \\
\hline M6_M_PC & $\begin{array}{l}\text { Unreinforced Masonry, reinforced } \\
\text { concrete floors, } 3-5 \text { floors, Pre-code } \\
\text { seismic standards }\end{array}$ & 0.0035 & 0.004 & 0.00001 & 0.00001 \\
\hline RC1_III_L_DCL & $\begin{array}{l}\text { Concrete Moment Frame, 1-3 floors, } \\
\text { seismic code with seismicity zone III, } \\
\text { Low ductility capacity }\end{array}$ & 0.0025 & 0.0003 & 0 & 0 \\
\hline RC1_III_M_DCL & $\begin{array}{l}\text { Concrete Moment Frame, 4-7 floors, } \\
\text { seismic code with seismicity zone III, } \\
\text { Low ductility capacity }\end{array}$ & 0.0025 & 0.0003 & 0 & 0 \\
\hline RC3_III_M_DCL & $\begin{array}{l}\text { Reinforced concrete Dual System, 4-7 } \\
\text { floors, seismic code with seismicity } \\
\text { zone III, Low ductility capacity }\end{array}$ & 0.0025 & 0.0003 & 0 & 0 \\
\hline RC3_III_H_DCL & $\begin{array}{l}\text { Reinforced concrete Dual System, } \geq 8 \\
\text { floors, seismic code with seismicity } \\
\text { zone III, Low ductility capacity }\end{array}$ & 0.0025 & 0.0003 & 0 & 0 \\
\hline RC1_II_L_DCM & $\begin{array}{l}\text { Concrete Moment Frame, 1-3 floors, } \\
\text { seismic code with seismicity zone II, } \\
\text { Medium ductility capacity }\end{array}$ & 0.0025 & 0.0003 & 0 & 0 \\
\hline RC1_II_M_DCM & $\begin{array}{l}\text { Concrete Moment Frame, 4-7 floors, } \\
\text { seismic code with seismicity zone II, } \\
\text { Medium ductility capacity }\end{array}$ & 0.0025 & 0.0003 & 0 & 0 \\
\hline RC1_II_H_DCM & $\begin{array}{l}\text { Concrete Moment Frame, } \geq 8 \text { floors, } \\
\text { seismic code with seismicity zone II, } \\
\text { Medium ductility capacity }\end{array}$ & 0.0025 & 0.0003 & 0 & 0 \\
\hline RC3_II_L_DCM & $\begin{array}{l}\text { Reinforced concrete Dual System, 1-3 } \\
\text { floors, seismic code with seismicity } \\
\text { zone II, Medium ductility capacity }\end{array}$ & 0.0025 & 0.0003 & 0 & 0 \\
\hline RC3_II_M_DCM & $\begin{array}{l}\text { Reinforced concrete Dual System, 4-7 } \\
\text { floors, seismic code with seismicity } \\
\text { zone II, Medium ductility capacity }\end{array}$ & 0.0025 & 0.0003 & 0 & 0 \\
\hline RC3_II_H_DCM & $\begin{array}{l}\text { Reinforced concrete Dual System, } \geq 8 \\
\text { floors, seismic code with seismicity } \\
\text { zone II, Medium ductility capacity }\end{array}$ & 0.0025 & 0.0003 & 0 & 0 \\
\hline
\end{tabular}

\section{7 (4) Estimation of the Population Affected}

To estimate the population affected by damage to buildings, with the maximum

579 possible resolution, it would be necessary to know the inhabitants for every of those

580 buildings in which SISMOTOOL calculates the damage. When there is no data from

581 population at this scale, an average of the damage parameter under study is used on the

582 minimum population unit for which data are available. In the current version of the

583 program, the Census Sections and the information provided by the National Institute of

584 Statistics have been used as a source of spatial data on the population (INE 2018).

In this way, SISMOTOOL can calculate, through the use of the ArcObjects 
587 (Pop_damage), (for example, the uninhabitability of the building, or the severity of injury i), 588 in each Census Section, with the following formula (Eq. 14):

589

$$
\text { Pop_damage }_{\text {CensusSecc }}=\text { PopTotal }_{\text {CensusSecc }} \frac{\sum_{\text {Building_CensusSecc }} \text { Pr_damage }}{\text { Frequency }}
$$

590

where: PopTotal CensusSecc $_{\text {is }}$ the total population; $\sum$ Building_CensusSecc $P r \_$damage is the sum of probabilities of damage for every Building; Frequency is the total number of Buildings.

592

(5) Economic losses due to structural damage

593

The economic losses caused by the structural damage are computed following

594 also the HAZUS-MH (FEMA 2013) approach (Eq. 15):

595

$\mathrm{CS}^{\mathrm{B}}=A^{B} \times \sum_{\text {Typ } \_\mathrm{i}}^{N B T} \sum_{\text {Dam_k }}^{N d s} \sum_{\text {Occupancy } \_j}^{N O C} \operatorname{Cost}_{j} \times \operatorname{Cost}_{j_{-} k} \times A_{i_{-} j} \times \operatorname{Pr}\left(\mathrm{Dam} \_\mathrm{i} \_\mathrm{k}\right) \times \operatorname{Pr}\left(\mathrm{Typ} \_\mathrm{i}\right)$

596

where: $N B T$ is the number of building typologies; $N d s$ is the number of damage states

$597(d s) ; N O C$ is the number of occupancy class, as defined by de user through a database

598 (Table 6); $C_{j}$ is the total structural replacement cost (euros $/ \mathrm{m}^{2}$ ) for a building with

599 occupancy class $j$, provided by the user through a database (Table 6 ); $C_{j_{-} k}$ is the ratio of

$600 C_{j}$ for damage state $k$, provided by the user through a database (Table 6 ); $A_{i_{-} j}$ is the ratio

601 of building areas with occupancy classes $j$, corresponding to the building typology $i$,

602 provided by the user through a database (Table 7); $\operatorname{Pr}\left(\mathrm{Dam} \_\mathrm{i} \_\mathrm{k}\right)$ is the damage

603 probability $k$ for a building of typology $i$; $\operatorname{Pr}($ Typ_i) is the probability that a building

604 belongs to typology $i ; A^{B}$ is the building area $\left(\mathrm{m}^{2}\right)$; and finally, $\mathrm{CS}^{\mathrm{B}}$ is the building

605 economic losses (euros) caused by the structural damage.

606

607 Table 6 Example of a default matrix for the definition of occupation classes and their structural costs, but they 608 can be modified by the user

\begin{tabular}{|l|l|l|l|l|l|}
\hline $\begin{array}{l}\text { OCCUPANCY } \\
\text { CLASS }\end{array}$ & $\begin{array}{l}\text { COST } \\
\text { (EUROS/M2) }\end{array}$ & $\begin{array}{l}\text { COST_j_1 } \\
\text { DAMAGE_1 }\end{array}$ & $\begin{array}{l}\text { COST_j_2 } \\
\text { DAMAGE_2 }\end{array}$ & $\begin{array}{l}\text { COST_j_3 } \\
\text { DAMAGE_3 }\end{array}$ & $\begin{array}{l}\text { COST_j_4 } \\
\text { DAMAGE_4 }\end{array}$ \\
\hline RESIDENTIAL_1 & 600 & 0.02 & 0.1 & 0.5 & 1 \\
\hline RESIDENTIAL_2 & 800 & 0.02 & 0.1 & 0.5 & 1 \\
\hline COMMERCIAL_1 & 900 & 0.01 & 0.07 & 0.4 & 1 \\
\hline COMMERCIAL_2 & 1000 & 0.01 & 0.07 & 0.4 & 1 \\
\hline
\end{tabular}




\begin{tabular}{|l|l|l|l|l|l|}
\hline INDUSTRIAL_1 & 500 & 0.01 & 0.05 & 0.3 & 1 \\
\hline AGRICULTURE_1 & 700 & 0.01 & 0.05 & 0.3 & 1 \\
\hline RELIGION_1 & 900 & 0.02 & 0.1 & 0.5 & 1 \\
\hline GOVERNMENT_1 & 800 & 0.02 & 0.1 & 0.5 & 1 \\
\hline EDUCATION_1 & 800 & 0.02 & 0.1 & 0.5 & 1 \\
\hline
\end{tabular}

610 Table 7 Example of a default matrix of building area ratios with a specific occupancy class, for each building

611 typology, but they can be modified by the user

612

\begin{tabular}{|c|c|c|c|c|c|c|c|c|c|}
\hline $\begin{array}{l}\text { BUILDING } \\
\text { TYPOLOGY }\end{array}$ & A_i_RES1 & A_i_RES2 & A_i_COM1 & A_i_COM2 & A_i_IND1 & A_i_AGR1 & A_i_REL1 & A_i_GOV1 & A_i_EDU1 \\
\hline M2.w_L & 1 & 0 & 0 & 0 & 0 & 0 & 0 & 0 & 0 \\
\hline M3.w_L & 1 & 0 & 0 & 0 & 0 & 0 & 0 & 0 & 0 \\
\hline M3.w_M & 1 & 0 & 0 & 0 & 0 & 0 & 0 & 0 & 0 \\
\hline M5.w_L & 0.5 & 0.5 & 0 & 0 & 0 & 0 & 0 & 0 & 0 \\
\hline M6_L_PC & 0.5 & 0.3 & 0.2 & 0 & 0 & 0 & 0 & 0 & 0 \\
\hline M6_M_PC & 0.5 & 0.3 & 0.2 & 0 & 0 & 0 & 0 & 0 & 0 \\
\hline RC1_III_L_DCL & 0.4 & 0.2 & 0.2 & 0.1 & 0.1 & 0 & 0 & 0 & 0 \\
\hline RC1_III_M_DCL & 0.4 & 0.2 & 0.2 & 0.1 & 0.1 & 0 & 0 & 0 & 0 \\
\hline RC3_III_M_DCL & 0.4 & 0.2 & 0.2 & 0.1 & 0.1 & 0 & 0 & 0 & 0 \\
\hline RC3_III_H_DCL & 0.4 & 0.2 & 0.2 & 0.1 & 0.1 & 0 & 0 & 0 & 0 \\
\hline RC1_IILL_DCM & 0.3 & 0.2 & 0.2 & 0.1 & 0.1 & 0.1 & 0 & 0 & 0 \\
\hline RC1_II_M_DCM & 0.3 & 0.2 & 0.2 & 0.1 & 0.1 & 0.1 & 0 & 0 & 0 \\
\hline RC1_II_H_DCM & 0.3 & 0.2 & 0.2 & 0.1 & 0.1 & 0.1 & 0 & 0 & 0 \\
\hline RC3_IILDCM & 0.3 & 0.2 & 0.1 & 0.1 & 0.1 & 0.05 & 0.05 & 0.05 & 0.05 \\
\hline RC3 II M DCM & 0.3 & 0.2 & 0.1 & 0.1 & 0.1 & 0.05 & 0.05 & 0.05 & 0.05 \\
\hline RC3_II_H_DCM & 0.3 & 0.2 & 0.1 & 0.1 & 0.1 & 0.05 & 0.05 & 0.05 & 0.05 \\
\hline
\end{tabular}

\section{$613 \quad$ 2.2.7 ELE using a Logic Tree}

In many cases, all the parameters needed to estimate correctly an earthquake

615 losses scenario have large uncertainties. SISMOTOOL has included a logic tree in order

616 to take into account the epistemic uncertainties, as proposed by Molina et al. (2010). As

617 shown in Figure 19, SISMOTOOL carries out the ELE computation for each one of the

618 branches of the logic tree and the final result is the weighted mean (according to the

619 weights given to each branch).

620 


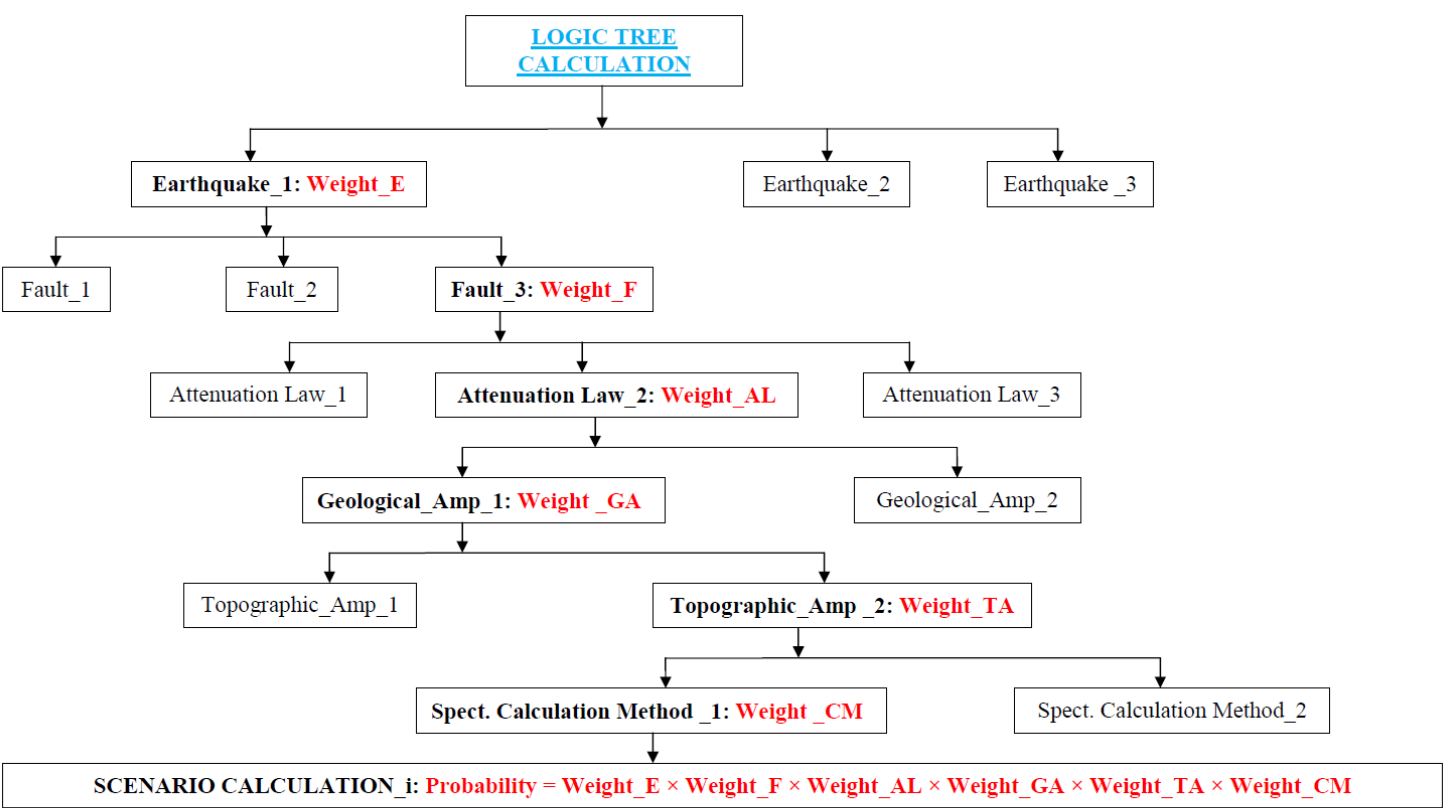

621

GLOBAL SCENARIO $=\sum$ Scenario_i $\times$ Probability_i

622

Fig. 19 Scheme for calculating the Seismic Damage Scenario using a Logic Tree

623

6243 Application of SISMOTOOL to Adra town

625

Adra town, with around 20,000 inhabitants (INE 2018), an urban area of $3.0 \mathrm{~km}^{2}$, and 3,700 buildings (SEC 2018), is located in the SW of Almería province (SE Spain). 627 According to the new seismic hazard map of Spain (IGN-UPM 2013), this region is one of 628 the most hazardous seismic areas with an estimated PGA at rock of $0.19 \mathrm{~g}$ and $0.24 \mathrm{~g}$ for 629 475 and 975 years return period, respectively. The presence of active local Quaternary faults close to urban areas (e.g. Sanz de Galdeano et al. 1995; García-Mayordomo et al. 2012) can generate catastrophic damage, even for moderate earthquakes, as revealed the 2011 Lorca earthquake of $5.2 \mathrm{M}_{\mathrm{w}}$ scale (IGN 2011; Navarro et al. 2014). Although the

633 instrumental seismicity in the region is characterized by frequent earthquakes with $M_{w} \leq$

6345.0 , an offshore earthquake happened in 1910 with epicenter in the Alboran Sea, $M_{w}=6.3$ 635 and $15 \mathrm{~km}$ epicentral distance to Adra (Morales et al. 2003), generated a macroseismic 636 intensity VII-VIII (EMS-98 scale) in the town (Vidal 1986). Historical seismicity shows 637 earthquakes placed in Almería province with epicentral distances to Adra smaller than $\mathbf{5 0}$ 
km (Vidal 1986; Espinar 1994) and epicentral macroseismic intensity $I_{0} \geq$ VIII, such as Almería (1487, 1522 and 1658) or Dalías (1804).

640 Therefore, SISMOTOOL has been used to compute the shakemap and damage 641 scenario assuming a repetition of the 1910 Adra earthquake $\left(M_{w} 6.3\right.$; focal depth $16 \mathrm{~km}$; 642 latitude: $36.58 \mathrm{~N}$; longitude: $3.08 \mathrm{~W}$; Adra fault). Morales et al. (2003) carried out an 643 exhaustive simulation of the PGA at rock due to this earthquake using empirical Green 644 functions and they concluded that the PGA values may reach $140 \mathrm{~cm} / \mathrm{s}^{2}$ in the epicentral 645 zone.

Spectral accelerations at rock and soil amplified for Adra town (site with higher acceleration) are compared in Figures 20 and 21 using different attenuation laws and soil

648 class amplification factors. As it can be seen, the Campbell and Bozorgnia (2013) (139 $649 \mathrm{~cm} / \mathrm{s}^{2}$ ), is the GMPE which provides a PGA at rock closer to the obtained by Morales et al. 650 (2003), followed by Ambraseys et al. (2005) (129 cm/s²), Akkar and Bommer (2010) (116 $\left.\mathrm{cm} / \mathrm{s}^{2}\right)$ and Chiou and Youngs (2014) $\left(117 \mathrm{~cm} / \mathrm{s}^{2}\right)$.

652

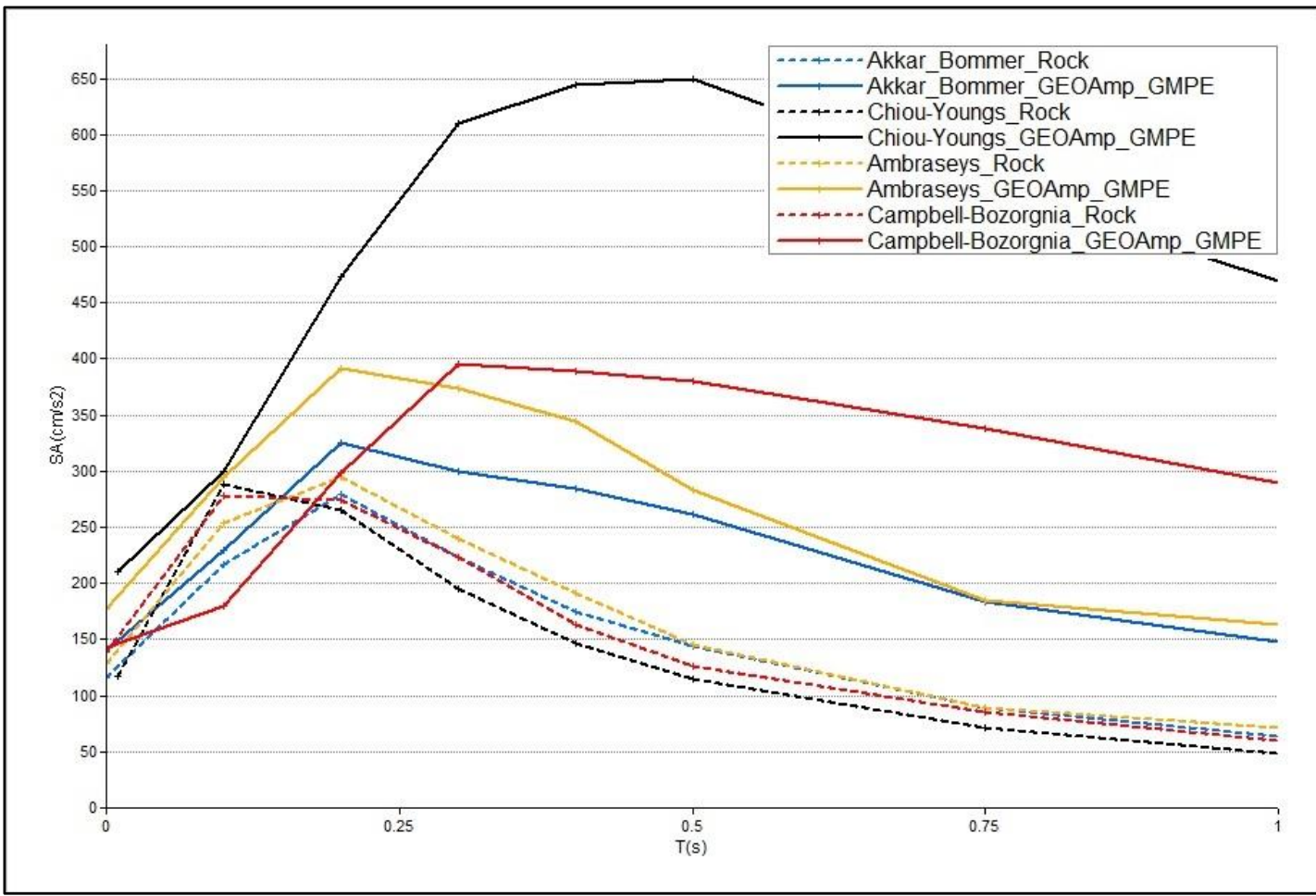

Fig. 20 Spectral acceleration for Adra town (site with higher acceleration), computed with SISMOTOOL using different attenuation laws and soil class amplification factors according to M1 method considering Vs30 values 
657

658

659

660

661

662

663

664

665

666

667

668

669

670

671

672

673

674

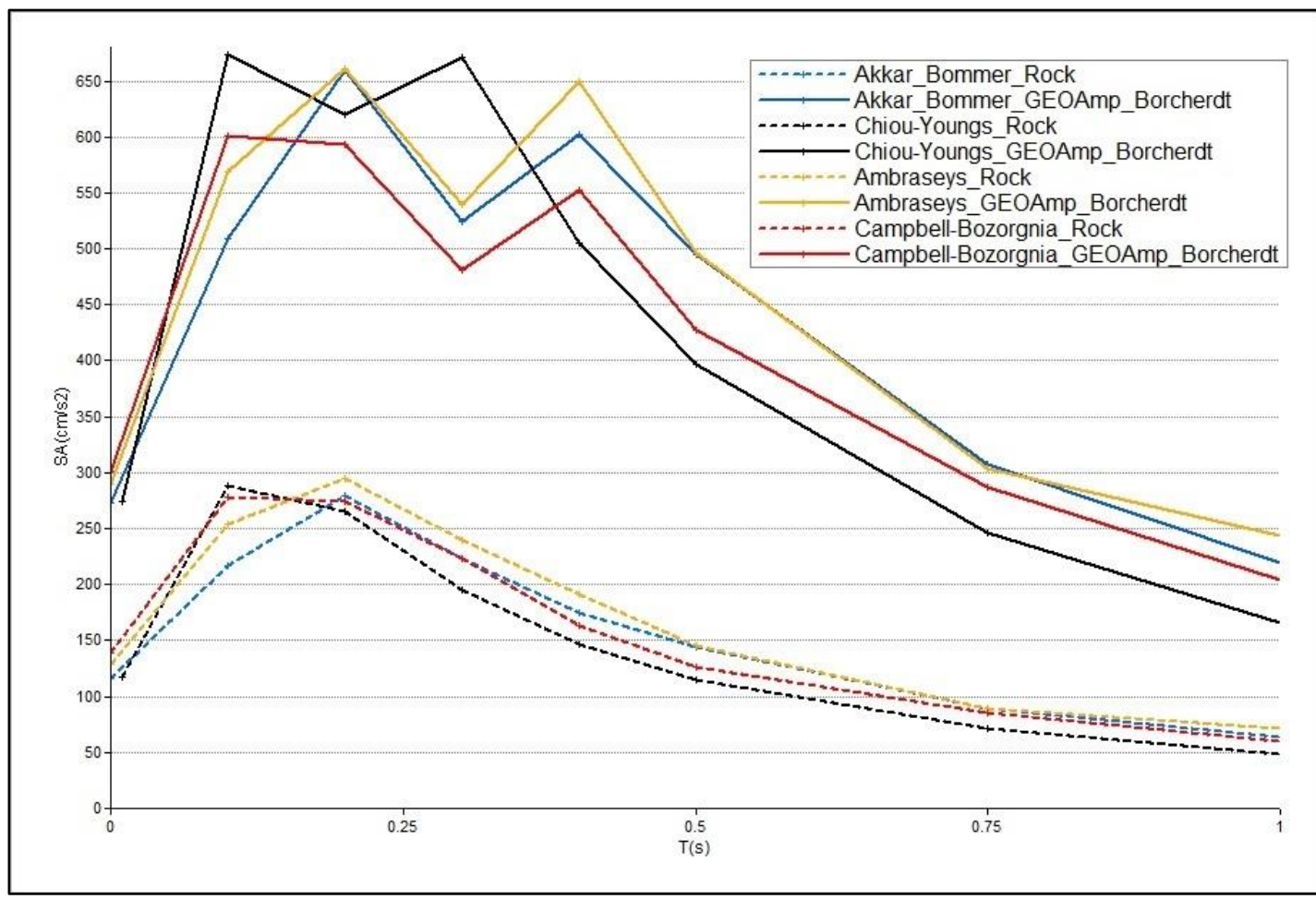

Fig. 21 Spectral acceleration for Adra town (site with higher acceleration), computed with SISMOTOOL using different attenuation laws and soil class amplification factors according to M2 method considering Vs30 values obtained through own correlation (Wald et al. 2011)

In order to compare with previously recorded earthquakes, a PGA at rock simulation has also been carried out for the 1994 Adra earthquake, described in Morales et al. (2002) ( $m_{b} 4.9$; focal depth $7 \mathrm{~km}$; latitude: $36.56 \mathrm{~N}$; longitude: $2.80 \mathrm{~W}$; Adra fault). In this paper authors stated that accelerograms were recorded at different IGN stations, whose PGA at rock data for the Adra station reached $30.5 \mathrm{~cm} / \mathrm{s}^{2}$. SISMOTOOL estimates PGA for the different attenuation laws and the results are: (1) IGN-UPM (2013), $8 \mathrm{~cm} / \mathrm{s}^{2}$; (2) Akkar and Bommer (2010), $25 \mathrm{~cm} / \mathrm{s}^{2}$; (3) Ambraseys et al. (2005), $32 \mathrm{~cm} / \mathrm{s}^{2}$; (4) Campbell and Bozorgnia (2013), $17 \mathrm{~cm} / \mathrm{s}^{2}$; (5) Chiou and Youngs (2014), $18 \mathrm{~cm} / \mathrm{s}^{2}$.

Comparing both simulations is noted that one of the main sources of uncertainties in any seismic hazard or risk estimation comes from the GMPE chosen. Therefore the user should take into account these uncertainties by applying a logic tree. 
676

To perform a validation test, the results obtained by SISMOTOOL have been compared with other results of shakemap (Martínez-Pagan et al. 2015) and damage 678 scenario (Molina et al. 2018) obtained for Adra town by using the same earthquake 679 scenario (Adra 1910) and different methodologies.

680

Figure 22 compares the distribution of PGA values obtained by SISMOTOOL for 681 Adra town using the GMPE proposed by Campbell and Bozorgnia (2017) and amplified by 682 M2 method (Fig. 22.a), with the results obtained by Martínez-Pagan et al. (2015) (Fig. 683 22.b). In the first case, the maximum PGA value is $302 \mathrm{~cm} / \mathrm{s}^{2}$, while Martínez-Pagan et al. 684 (2015) estimates maximum PGA value of $350 \mathrm{~cm} / \mathrm{s}^{2}$.

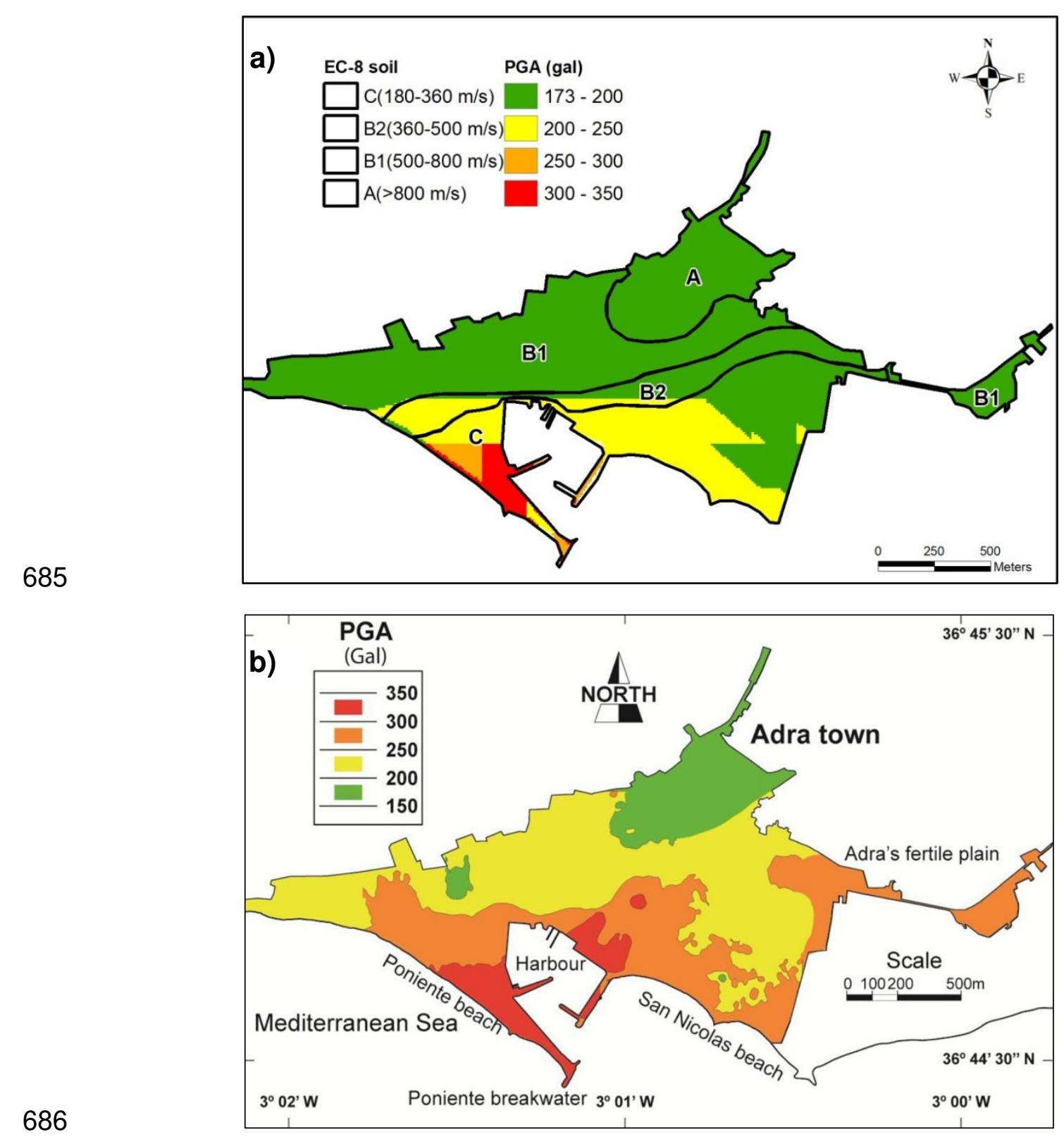


688

Mean damage ratio to buildings in Adra town were computed using SISMOTOOL 690 for different GMPEs and with the analytical method (Fig. 23). The performance point was 691 obtained using the MADRS and I-DCM methods. The differences between MADRS and IDCM methods are not very important (around a 5\% to 10\% higher with I-DCM); however, 693 the use of the soil class amplification factors according to M2 method instead of M1 is 694 responsible of a higher increase of the damage results except for the Chiou and Youngs 695 GMPE. This is due to the similar behaviour of the amplified ground motion (Fig. 20 and 696 21).

697

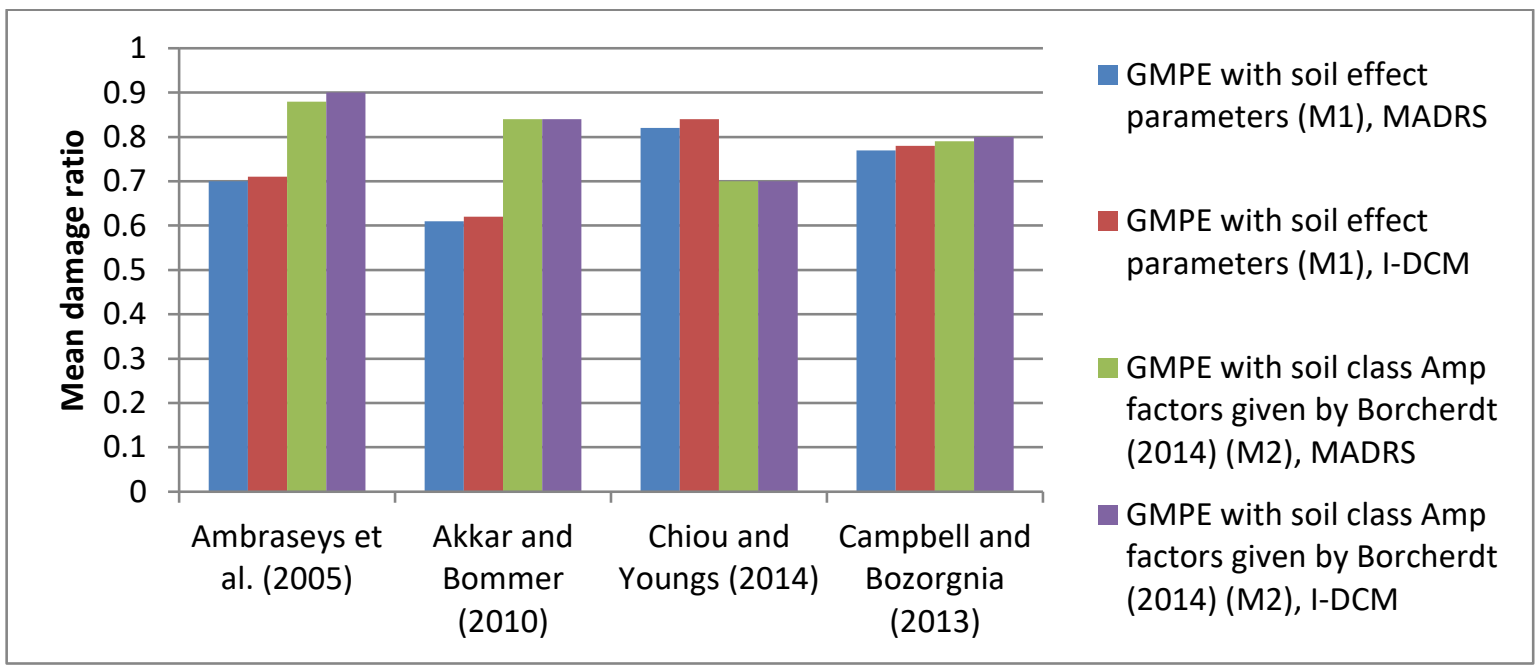

Fig. 23 Mean damage to Buildings in Adra town, computed by SISMOTOOL for the 1910 Adra earthquake

699

700

The comparison of uninhabitable buildings results (Fig. 24), obtained by SISMOTOOL simulation for the amplified PGA proposed by Martínez-Pagán et al. (2015) with a normalized elastic response spectrum according to Eurocode 8 (Fig 24.a), and with respect to those obtained by Molina et al. (2018) using the same spectrum and SELENA software (Fig. 24.b), shows good agreement between both tools. 

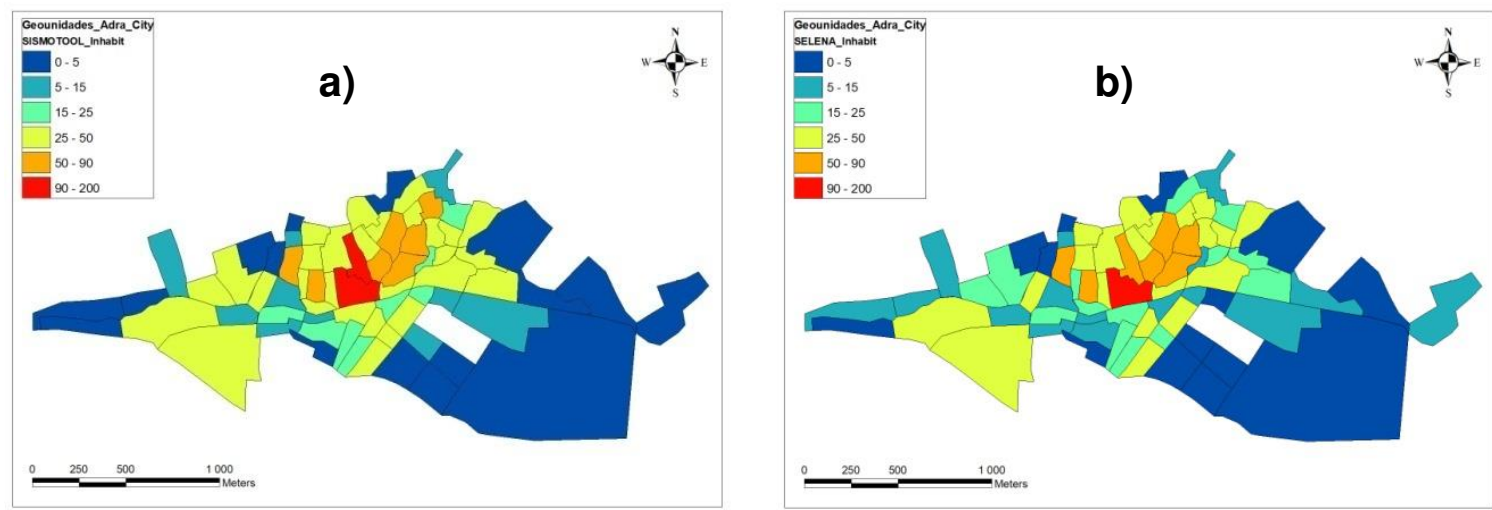

Fig. 24 Comparison of uninhabitable buildings in Adra town: a) computed by SISMOTOOL using the PGA shakemap proposed by Martínez-Pagán et al. (2015); b) obtained by Molina et al. (2018) using the same shakemap and computed by SELENA

708

Additionally, SISMOTOOL allows a sensitivity study of the results when using the normalized spectra according to Eurocode 8 (CEN 2004a) and the specific spectrum obtained from the GMPE. For example, the uninhabitable buildings using the normalized spectrum are 2,000 approximately while there are only 310 builidings when using the specific spectrum from Ambraseys et al. (2005) amplified by M2 method. These results are in agreement with Haldar et al. (2013) who also observed significant differences in the risk estimation for the code design spectra and the NGA model.

In order to analyze the influence of resonance effect on uninhabitable buildings, a comparison between the results obtained from empirical methods was made, using the specific elastic response spectra of GMPE according to Ambraseys et al. (2005), soil class amplification factors by M2 method and vulnerability index with Milutinovic and

720 Trendafiloski (2003) modifiers, with and without resonance modifier (Fig. 25). If the

721 resonance modifier is not included, the total number of uninhabitable buildings is 868 , 722 while considering the resonance modifier the number of uninhabitable buildings increases 723 by a $14.4 \%$. Figure 25 identifies also the areas where the soil-structures resonance is 724 increasing the damage allowing the users to adopt seismic management decisions. 
726
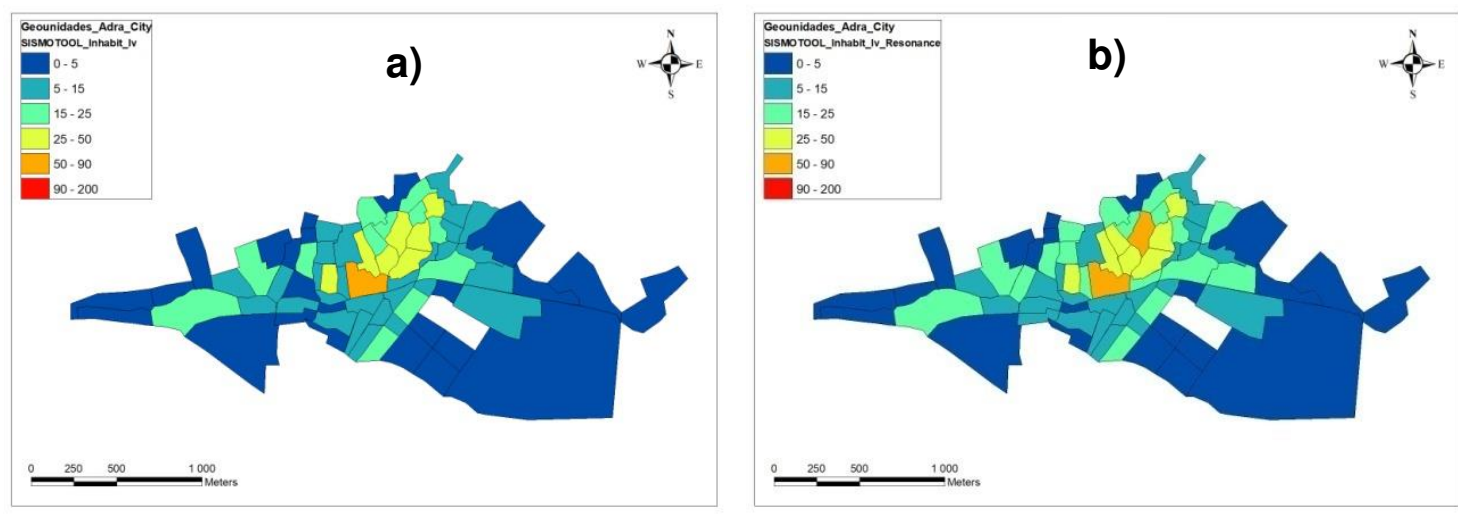

Fig. 25 Comparison of uninhabitable buildings considering: a) without resonance modifier; b) the resonance modifier

\section{Concluding Remark}

The development of SISMOTOOL was due to the need of providing to Civil Protection a complete and versatile tool for the Planning and Management of Seismic Emergencies. To achieve this objective, it has been considered important to find the following requirements: (1) The highest possible resolution in the results, for example damage computation at the building level, or maps with a 5-10 m pixel resolution; (2) High computing efficiency to obtain results allowing "real-time" decisions. For a small city as Adra, the computation time of the damage scenario is around $15 \mathrm{~s}$, while at the regional level (e.g. the case of the province of Almería) is about $90 \mathrm{~s}$; (3) The possibility of choosing different scales of calculation (from local to regional), which results in computing efficiency; (4) A friendly-user interface developed specifically for emergency managers allowing an easy interaction with other spatial databases.

Additionally, in the process of developing the previous objectives, a series of added-value tools were coded: (1) Regional processing of amplifications of ground motion by geology (topographic slope as a proxy, including specific correlation) and by topographic effects (according to Eurocode 8), at a resolution (5 to $10 \mathrm{~m}$ ); (2) Automatic extraction and analysis of vulnerable elements (buildings). Furthermore, the user can define statistical parameters to automatically estimate the vulnerability (empirically or analytically) of each building; (3) Development of an own database of spatial distribution 
of the population, to obtain as a result in the simulation, the population affected (Homeless

750

751

752

753

754

755

756

757

758

759

760

761

762

763

764

765

766

767

768

769

770

771

772 functionality is of great interest in the calculation of scenarios in regions where

773

774

775 people, Human casualties).

SISMOTOOL allows the user to choose between several computation options: (1)

Different ways of defining the basic parameters of the earthquake, choosing it from an included database and selection of the corresponding fault; (2) Design and edition of a database of possible earthquakes for the simulated scenario; (3) Different ground motion prediction models (GMPE) and ground motion amplification methods; (4) Damage estimation using the empirical method (EMS-98, Vulnerability Index) or the analytical (MADRS, IDCM); (5) Possibility of choosing between the specific response spectrum predicted by the GMPE or the code design spectrum according to Eurocode 8; (6) Estimation of uninhabitable buildings, human casualties, population affected and structural economic losses.

All the scripts are accessible and adaptable through the VB.NET Visual Studio project, allowing users the development of new tools. Therefore, SISMOTOOL can be applied to any region of the world.

Using the mentioned options, SISMOTOOL can carry out a sensitivity analysis of the damage and losses results to the input parameters, allowing to quantify uncertainties. An example is shown for the city of Adra, pointing out the huge uncertainty related with the selection of the GMPE and the importance of using ground motion values from recorded earthquake to choose one or more GMPE models and, besides, these uncertainties can be included in the damage and losses results using a logic tree.

SISMOTOOL incorporates in the estimation of site effects due to the soil class, the determination of the value of Vs30 from the topographic slope (proxy method). This experimental measures are not available, or where it is intended to obtain a specific correlation better adapted to those measures. Moreover, topographic amplifications can also be automatically deduced from that slope. 
777 The ground motion amplification from geological empirical factors given by Borcherdt 778 (2014) provides, in general, higher amplified ground motion than the obtained with GMPE model with soil coefficients, with the exception of Chiou and Youngs (2014). One of the main advantages of SISMOTOOL is the possibility of taking into consideration the soil-structures resonance using vulnerability modifiers. The results prove that the inclusion of the resonance modifier significantly increases the damage.

Finally, SISMOTOOL has been proven as an effective tool in the generation of

\section{REFERENCES}

787

788

789

790

791

792

793

794

795

796

797

798

799

800

801

802

803

804

805

806

Aki K (1957) Space and time spectra of stationary stochastic waves, with special reference to microtremors. Bull Earthq Res Inst, 35: 415-456.

Akkar S, Boomer JJ (2010) Empirical Equations for the Prediction of PGA, PGV, and Spectral Accelerations in Europe, the Mediterranean Region, and the Middle East. Seismological Research Letters, 81: 195206.

Alguacil G, Vidal F, Navarro M, García-Jerez A, Pérez-Muelas J (2014) Characterization of earthquake shaking severity in the town of Lorca during the May 11, 2011 event. Bulletin of Earthquake Engineering, 12(5): 1889-1908.

Ambraseys NN, Douglas J, Sarma SK (2005) Equations for the estimation of strong ground motions from shallow crustal earthquakes using data from Europe and the Middle East: Horizontal peak ground acceleration and spectral acceleration. Bulletin of Earthquake Engineering, 3(1): 1-53.

Anagnostopoulosa S, Providakisb S, Salvaneschic P, Athanasopoulosa G, Bonacinad G (2008) SEISMOCARE: an efficient GIS tool for scenario-type investigations of seismic risk of existing cities. Journal of Soil Dynamics and Earthquake Engineering 28: 73-78.

Benito B, Capote R, Murphy P, Gaspar-Escribano JM, Martinez-Diaz JJ, Tsige M et al. (2007a) An Overview of the Damaging and Low Magnitude Mw 4.8 La Paca Earthquake on 29 January 2005: Context, Seismotectonics, and Seismic Risk Implications for Southeast Spain. Bulletin of the Seismological Society of America, 97(3): 671-690.

Benito B, Navarro M, Murphy P, Vidal F, Gaspar-Escribano J, Jiménez ME, García MJ (2007b) Riesgo Sísmico en Andalucía. Proyecto SISMOSAN, V1, V2, V3, V4. UPM, Madrid. 
Bommer J, Stafford PJ (2020) Selecting ground-motion models for site-specific PSHA: Adaptability versus Applicability. Bulletin of the Seismological Society of America, 110(6): 2801-2815.

809 Borcherdt RD (1994) Estimates of Site-Dependent Response Spectra for Design (Methodology and Justification). Earthquake Spectra, 10(4): 617-653.

811 Borcherdt RD (2014) Implications of next generation attenuation ground motion prediction equations for site 812 coefficients used in earthquake resistant design. Earthquake Engineering \& Structural Dynamics, 43: $1343-1360$

814 Campbell KW, Bozorgnia Y (2013) NGA-West2 2013, Campbell-Bozorgnia Ground Motion Model for the Horizontal Components of PGA, PGV, and 5\% Damped Elastic Pseudo-Acceleration Response Spectra for Periods Ranging from 0.01 to $10 \mathrm{~s}$. Pacific Earthquake Engineering Research Center, Report 2013/06.

Cardona OD, Ordaz MG, Reinoso E, Yamín-Lacouture LE, Barbat-Barbat HA (2012) CAPRA Comprehensive Approach to Probabilistic Risk Assessment: international initiative for risk management effectiveness. A: World Conference on Earthquake Engineering. 15th World Conference on Earthquake Engineering. Lisboa 2012, pp. 1-10.

CEN (2004a) EN 1998-1: 2004. Eurocode 8: Design of structures for earthquake resistance. Part 1: General

CEN (2004b) EN 1998-5: 2004. Eurocode 8: Design of structures for earthquake resistance. Part 5: Foundations, retaining structures and geotechnical aspects. European Committee for

830 Chiou Brian SJ, Youngs Robert R (2014) Update of the Chiou and Youngs NGA Ground Motion Model for Average Horizontal Component of Peak Ground Motion and Response Spectra. Earthquake Spectra,

Coburn A, Spence R, Pomonis A (1992) Factors determining human casualty levels in earthquakes: mortality prediction in building collapse. 10th World Conference on Earthquake Engineering. Balkema,

836 Espinar M (1994) Los estudios de sismicidad histórica en Andalucía: Los terremotos históricos de la provincia de Almería. Instituto de Estudios Almerienses, acta no 16, pp. 183-206.

838 Federal Emergency Management Agency (FEMA) (1999) In: HAZUS®99: Earthquake Loss Estimation Methodology, User Manual. Federal Emergency Management Agency, Washington, DC, pp. 314.

840 Federal Emergency Management Agency (FEMA) (2005) Improvement of Non linear Static Seismic Analysis Procedures. Federal Emergency Management Agency, Washington, DC, pp. 392. 

Methodology Maintenance. Technical and User Manuals. Federal Emergency Management Agency, Washington, DC, pp. 718.

Gallipoli MR, Mucciarelli M, Šket-Motnikar B, Zupanc ic' P, Gosar A, Prevolnik S, Herak M, Stipc`evic' J, Herak D, Milutinovic' Z, Olumc'eva T (2010) Empirical estimates of dynamic parameters on a large set of European buildings. Bulletin of Earthquake Engineering 8: 593-607.

García-Jerez A, Navarro M, Alcalá FJ, Luzon F, Pérez-Ruiz JA, Enomoto T et al. (2007) Shallow velocity structure using joint inversion of array and $\mathrm{h} / \mathrm{v}$ spectral ratio of ambient noise: The case of Mula town (SE of Spain). Soil Dynamics and Earthquake Engineering, 27(10): 907-919.

García-Mayordomo J, Insua-Arévalo JM, Martínez-Díaz JJ, Jiménez-Díaz A, Martín-Banda R, MartínMasana E, Perea H, Martín-González F, Giner-Robles J, Nemser ES, Cabral J and the QAFI Compilers Working Group (2012) The Quaternary Faults DB of Iberia (QAFI v.2.0), Journal of Iberian Geology, 38(1): 285-302.

Giovinazzi S, Lagomarsino S (2002) WP04: Guidelines for the implementation of the I level methodology for

Haldar P, Singh Y, Lang DH, Paul DK (2013) Comparison of seismic risk assessment based on macroseismic intensity and spectrum approaches using 'SeisVARA'. Soil Dynamics and Earthquake Engineering, 48: $267-281$

[dataset] IDEA (2010) http://www.ideandalucia.es. Last accessed 1.06.19.

[dataset] IGME (1983) Mapa Geológico de España a escala 1:50000. Hoja 1057, Adra. Aldaya F, Baena J, Ewert K, Granados LF, Pan Arana T, Fernández-Luanco MC, Ruiz P. Available at http://info.igme.es/cartografiadigital/geologica.

[dataset] IGME (2015) QAFI v.3: Quaternary Active Faults DB of Iberia. García-Mayordomo J, Insua-Arévalo JM, Martínez-Díaz JJ, Jiménez-Díaz A, Martín-Banda R, Martín-Alfageme S, Álvarez-Gómez JA, Rodríguez-Peces M, Pérez-López R, Rodríguez-Pascua MA, Masana E, Perea H, Martín-González F, Giner-Robles J, Nemser ES, Cabral J and the QAFI Compilers Working Group (2012) The Quaternary Faults DB of Iberia (QAFI v.2.0), Journal of Iberian Geology, 38(1), pp. 285-302. Accessed "DATE”, from IGME web site: http://info.igme.es/QAFI.

IGN (2011) Instituto Geográfico Nacional. Serie terremoto NE Lorca (Murcia), Madrid. Available at http://www.ign.es/. 

Centro Nacional de Información Geográfica, Madrid.

879 [dataset] IGN (2019) https://www.ign.es/web/ign/portal/sis-catalogo-terremotos. Last accessed 1.06.19.

880 [dataset] INE (2018) https://www.ine.es. Last accessed 1.06.19.

881 Lagomarsino S, Giovinazzi S (2006) Macroseismic and mechanical models for the vulnerability and damage 882 assessment of current buildings. Bulletin of Earthquake Engineering, 4: 415-443.

883 Martínez-Pagán P, Navarro M, Pérez-Cuevas J, Vidal F (2015) Application of SPAC and MASW Techniques to Earthquake-shaking Scenarios. The Case of the 1993-1994 Adra Earthquakes. In: Proccedings of the 21st European Meeting of Environmental and Engineering Geophysics-Near Surface Geosciences, Turin, Italy, pp. 1-5.

Martínez-Pagán P, Navarro M, Pérez-Cuevas J, Alcalá FJ, García-Jerez A, Vidal F (2018) Shear-wave velocity structure from MASW and SPAC methods: The case of Adra town, SE Spain. Near Surface Geophysics, 16: 356-371.

Milutinovic ZV, Trendafiloski GS (2003) WP04. Vulnerability of current buildings. RISK-UE project: An advanced approach to earthquake risk scenarios with applications to different European towns. Contract No.EVK4-CT-2000-00014. Institute of Earthquake Engineering and Engineering Seismology (IZIIS).

Molina S, Lang DH, Lindholm CD (2010) SELENA. An open-source tool for seismic risk and loss assessment using a logic tree computation procedure. Computers \& Geosciences, 36: 257-269.

Molina S, Navarro M, Martínez-Pagán P, Pérez-Cuevas J, Vidal F, Navarro D, Agea-Medina N (2018) Potential damage and losses in a repeat of the 1910 Adra (Southern Spain) earthquake. Springer

Morales J, Benito B, Luján M (2002) Simulation of ground motion in south-east of Spain, using strong motion records and historical information. 12th European Conference on Earthquake Engineering, September 2002, paper reference 654.

Morales J, Benito B, Luján M (2003) Expected ground motion in the south-east of Spain due to an earthquake in the epicentral area of the 1910 Adra earthquake. Journal of Seismology, 7(2): 175-192.

Moreno R, Lantada N, Bonett R, Barbat A, Pujades L (2003) WP4: Vulnerability assessment of current buildings. Capacity and fragility of the Barcelona's residential buildings. RISK-UE project: An advanced approach to earthquake risk scenarios with application to different European towns, Technical presentation CIMNE Group.

Navarro M, Sánchez FJ, Enomoto T, Vidal F, Rubio S (2000) Relation between the predominant periods of soil ant the damage distribution after Mula 1999 earthquake. Sixth International Conference on Seismic Zonation (6ICSC). 12 to 15-11-00, Palm Spring, California, USA. 
Navarro M, Vidal F, Feriche M, Enomoto T, Sánchez FJ, Matsuda I (2004) Expected ground RC buildings structures resonance phenomena in Granada city (southern Spain). 13th World Conference on Earthquake Engineering. Paper No. 3308, Vancouver, B.C., Canada, August 1-6, 2004.

914 Navarro M, Vidal F, Enomoto T, Alcalá FJ, Sánchez FJ, Abeki N (2007) Analysis of site effects weightiness on RC building seismic response. The Adra (SE Spain) example. Earthquake Engineering and Structural Dynamics, 36: 1363-1383.

Navarro M, García-Jerez JA, Alcalá FJ, Vidal F, Enomoto T (2014) Local Site Effect Microzonation of Lorca town (southern Spain). Bulletin of Earthquake Engineering, 12(5): 1933-1959.

NGA-West2 (2013) Project by the Pacific Earthquake Engineering Research Center (PEERS) to improve Next Generation Attenuation models for active tectonic regions such as California.

Oliveira CS, Navarro M (2010) Fundamental periods of vibration of RC buildings in Portugal from in-situ experimental and numerical techniques. Bulletin of Earthquake Engineering, 8: 609-642.

Pagani M, Monelli D, Weatherill G, Danciu L, Crowley H, Silva V, Henshaw P, Butler L, Nastasi M, Panzeri L, Simionato M, Vigano D (2014) OpenQuake Engine: An Open Hazard (and Risk) Software for the Global Earthquake Model. Seismological Research Letters; 85(3): 692-702.

Park CB, Miller RD (2008) Roadside passive multichannel analysis of surface wave (MASW). Journal of Environmental and Engineering Geophysics, 13(1): 1-11.

Sanz de Galdeano C, Lopez Casado C, Delgado J, Peinado MA (1995) Shallow seismicity and active faults in

[dataset] SEC (2018) https://www.sedecatastro.gob.es. Last accessed 1.06.19.

Sedan O, Negulescu C, Terrier M, Roulle A, Winter T, Bertil D (2013) Armagedom. A Tool for Seismic Risk Assessment Illustrated with Applications. Journal of Earthquake Engineering, 17(2): 253-281.

SES (2002) Dirección General de Protección Civil, Instituto Geográfico Nacional: Estimación rápida preliminar de daños potenciales en España por terremotos: Simulación de Escenarios Sísmicos.

Vidal F (1986) Sismotectónica de la Región Béticas-Mar de Albarán. Tesis Doctoral, Universidad de Granada,

Vidal F, Navarro M, Aranda C, Enomoto T (2014) Changes in dynamic characteristics of Lorca RC buildings from pre- and post-earthquake ambient vibration data. Bulletin of Earthquake Engineering, 12(5): 2095-2110.

Villacis CA, Cardona CN (1999) RADIUS Methodology. Guidelines for the Implementation of Earthquake Management Projects Geohazard International. Palo Alto, California, pp. 130. https://www.geohaz.org/projects/radius.html. Last accessed 1.06.19. 
Wald DJ, Allen TI (2007) U. S. Geological Survey, Golden, CO, 80401. Topographic Slope as a Proxy for Seismic Site Conditions and Amplification. Bulletin of the Seismological Society of America, 97: 13791395.

947 Wald DJ, McWhirter L, Thompson E, Hering AS (2011) A New Strategy for Developing Vs30 Maps. 4th IASPEI/IAEE International Symposium: Effects of Surface Geology on Seismic Motion, August 2011. Wells DL, Coppersmith KJ (1994) New Empirical Relationships Among Magnitude, Rupture Length, Rupture Width and Surface Displacement. Bulletin of the Seismological Society of America, 84: 974-1002.

\section{$951 \quad$ Appendix 1}

952 Procedure to obtain the points of intersection between the bilinear capacity curve and the response 953 spectrum.

954 This spectrum is approximated in the form of straight lines between the values $\left(S d_{T i}, S a_{T i}\right)$ 955 determined from the attenuation laws (Fig. 1). Given the possible high number of buildings to be 956 analyzed, special emphasis is done on the calculation efficiency of the intersection algorithms, 957 thus, applying equation (1) from the first section $\left(S a_{T 0}\right.$ to $\left.S a_{T I}\right)$ of the response spectrum, and ending when the condition $A_{T i+1}\left(T_{e}\right)>S a_{T i+l}$ will be found to obtain $S d e$.

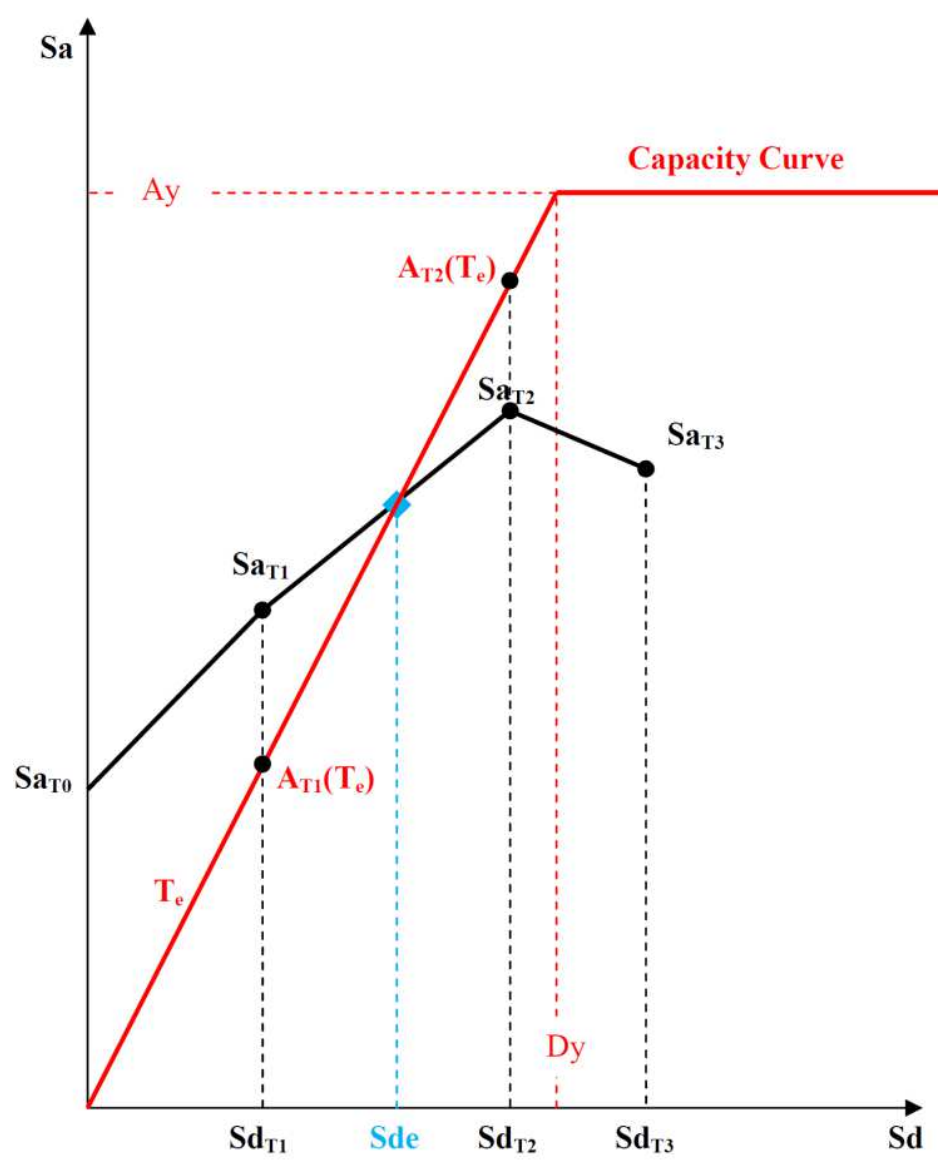


962 If $A_{T i+1}(T e)>S a_{T i+1} \Rightarrow \quad$ Slope $=\frac{\left(S a_{T i+1}-S a_{T i}\right)}{\left(S d_{T i+1}-S d_{T i}\right)} \quad$ Intercept $=S a_{T i+1}-$ Slope $\cdot S d_{T i+1}$

963

$$
S d e=\frac{\text { Intercept }}{\left(\frac{A y}{D y}-\text { Slope }\right)}
$$

\section{Appendix 2}

965 Least squares adjustment of the Normal distribution $\Phi\left(\frac{1}{\beta_{d s}} \ln \left(\frac{S d}{S d_{d s}}\right)\right)$ to the points in Table 4, to

966 obtain the standard deviation $\beta d s$ for damage 1 or Slight (Gauss-Newton method).

967 To minimize the residual function $\left(\mathrm{S}_{1}\right)$ with respect to the parameter $\beta_{1}$ (Eq. 1):

$$
\begin{gathered}
968_{1}^{8}=r_{1}^{2}+r_{2}^{2}+r_{3}^{2}+r_{4}^{2}=\left[\left(1-P_{\beta 2}(1)\right)-\Phi\left(\frac{1}{\beta_{1}} \ln \left(\frac{S d_{2}}{S d_{1}}\right)\right)\right]^{2}+\left[\left(1-P_{\beta 3}(1)\right)-\Phi\left(\frac{1}{\beta_{1}} \ln \left(\frac{S d_{3}}{S d_{1}}\right)\right)\right]^{2}+\left[\left(1-P_{\beta 4}(1)\right)-\Phi\left(\frac{1}{\beta_{1}} \ln \left(\frac{S d_{4}}{S d_{1}}\right)\right)\right]^{2} \\
969 \\
r_{1}=P_{\beta 1}(1)-\Phi\left(\frac{1}{\beta_{1}} \ln \left(\frac{S d_{1}}{S d_{1}}\right)\right)=0
\end{gathered}
$$

970

$$
\frac{\partial S_{1}}{\partial \beta_{1}}=0
$$

971 To solve this equation it is necessary to use a numerical method (in this case Gauss-Newton),

972 given the complexity of the approximation function used to evaluate $\Phi$. In this way, an iterative

973 process is carried out and a first initial value is given to $\beta_{l}$ (Eq. 2). For each iteration $k$ :

974

$$
\beta_{1} \approx \beta_{1}^{k+1}=\beta_{1}^{k}+\Delta \beta_{1}^{k}
$$

$975 \Phi\left(\frac{1}{\beta_{1}} \ln \left(\frac{S d_{i}}{S d_{1}}\right)\right) \approx \Phi\left(\frac{1}{\beta_{1}^{k}} \ln \left(\frac{S d_{i}}{S d_{1}}\right)\right)+\frac{\partial\left(\Phi\left(\frac{1}{\beta_{1}^{k}} \ln \left(\frac{S d_{i}}{S d_{1}}\right)\right)\right)}{\partial \beta_{1}}\left(\beta_{1}-\beta_{1}^{k}\right)=\Phi\left(\frac{1}{\beta_{1}^{k}} \ln \left(\frac{S d_{i}}{S d_{1}}\right)\right)+J_{i}^{k} \Delta \beta_{1}^{k}$

$97,6=\left(1-P_{\beta i}(1)\right)-\Phi\left(\frac{1}{\beta_{1}} \ln \left(\frac{S d_{i}}{S d_{1}}\right)\right)=\left(1-P_{\beta i}(1)\right)-\Phi\left(\frac{1}{\beta_{1}^{k}} \ln \left(\frac{S d_{i}}{S d_{1}}\right)\right)+\Phi\left(\frac{1}{\beta_{1}^{k}} \ln \left(\frac{S d_{i}}{S d_{1}}\right)\right)-\Phi\left(\frac{1}{\beta_{1}} \ln \left(\frac{S d_{i}}{S d_{1}}\right)\right)=\Delta P_{\beta i}^{k}-J_{i}^{k} \Delta \beta_{1}^{k}$

977

for $i=2,3,4$

978

$$
\frac{\partial S_{1}}{\partial \beta_{1}}=0 \rightarrow J_{2}^{k} \Delta P_{\beta 2}^{k}+J_{3}^{k} \Delta P_{\beta 3}^{k}+J_{4}^{k} \Delta P_{\beta 4}^{k}=\left(\left(J_{2}^{k}\right)^{2}+\left(J_{3}^{k}\right)^{2}+\left(J_{4}^{k}\right)^{2}\right) \Delta \beta_{1}^{k} \rightarrow
$$




$$
\Delta \beta_{1}^{k}=\frac{J_{2}^{k} \Delta P_{\beta 2}^{k}+J_{3}^{k} \Delta P_{\beta 3}^{k}+J_{4}^{k} \Delta P_{\beta 4}^{k}}{\left(\left(J_{2}^{k}\right)^{2}+\left(J_{3}^{k}\right)^{2}+\left(J_{4}^{k}\right)^{2}\right)}
$$

980 A convergence criterion of $\left|\Delta \beta_{I}{ }^{k} / \beta_{I}{ }^{k}\right|<0.001$ is set. It is also important to bear in mind that it

981 may happen that this iterative process does not converge, in which case the initial value of $\beta_{1}$ is 982 changed and the iterations are started again.

983 To calculate the Jacobian, another algorithm has been designed that performs a numerical derivative (Eq. 3):

$$
J_{i}^{k}=\frac{\partial\left(\Phi\left(\frac{1}{\beta_{1}^{k}} \ln \left(\frac{S d_{i}}{S d_{1}}\right)\right)\right)}{\partial \beta_{1}}=\lim _{h \rightarrow 0}\left(\frac{\Phi\left(\frac{1}{\beta_{1}^{k}+h} \ln \left(\frac{S d_{i}}{S d_{1}}\right)\right)-\Phi\left(\frac{1}{\beta_{1}^{k}} \ln \left(\frac{S d_{i}}{S d_{1}}\right)\right)}{h}\right)
$$

986

\section{List of number of columns of the figures and graphic program used to create them:}

Figure 1: 2-column. Created with ArcGis.

Figure 2: 2-column. Created with MSOffice.

990 Figure 3: 2-column. Created with MSOffice.

991 Figure 4: 2-column. Created with ArcGis.

992 Figure 5: single-column. Created with MSOffice.

993 Figure 6: single-column. Created with MSOffice.

994 Figure 7: 2-column .Created with ArcGis.

995 Figure 8: 2-column. Created with ArcGis.

996 Figure 9: 2-column. Created with ArcGis.

997 Figure 10: 2-column. Created with ArcGis.

998 Figure 11: 2-column. Created with ArcGis.

999 Figure 12: 1.5-column. Created with ArcGis.

1000 Figure 13: 1.5-column. Created with ArcGis.

1001 Figure 14: single-column. Created with ArcGis

1002 Figure 15: single-column. Created with ArcGis.

1003 Figure 16: 2-column. Created with MSOffice.

1004 Figure 17: 2-column. Created with ArcGis.

1005 Figure 18: single-column. Created with MSOffice.

1006 Figure 19: 2-column. Created with MSOffice.

1007 Figure 20: 2-column. Created with ArcGis. 
1008 Figure 21: 2-column. Created with ArcGis.

1009 Figure 22: 1.5-column. Created with ArcGis.

1010 Figure 23: 2-column. Created with MSOffice.

1011 Figure 24: 2-column. Created with ArcGis.

1012 Figure 25: 2-column. Created with ArcGis.

1013 Figure 1 (Appendix 1): single-column. Created with MSOffice.

1014 All figures should use color in printing 